\title{
Forecasting with Medium and Large Bayesian VARs
}

\author{
Gary Koop \\ University of Strathclyde
}

February 2010

\begin{abstract}
This paper is motivated by the recent interest in the use of Bayesian VARs for forecasting, even in cases where the number of dependent variables is large. In such cases, factor methods have been traditionally used but recent work using a particular prior suggests that Bayesian VAR methods can forecast better. In this paper, we consider a range of alternative priors which have been used with small VARs, discuss the issues which arise when they are used with medium and large VARs and examine their forecast performance using a US macroeconomic data set containing 168 variables. We find that Bayesian VARs do tend to forecast better than factor methods and provide an extensive comparison of the strengths and weaknesses of various approaches. Our empirical results show the importance of using forecast metrics which use the entire predictive density, instead of using only point forecasts.

Keywords: Bayesian, Minnesota prior, stochastic search variable selection, predictive likelihood

Acknowledgements: I would like to thank Dimitris Korobilis for helpful discussions. Some of the Matlab programs used in this paper are extensions of the ones available on our website:

http://personal.strath.ac.uk/gary.koop/bayes_matlab_code_by_koop_and_korobilis.html
\end{abstract}




\section{Introduction}

Vector autoregressive (VAR) models have a long and successful tradition in the forecasting literature (e.g. Doan, Litterman and Sims, 1984 and Litterman, 1986). VARs are parameter-rich models and shrinkage of various sorts has been found to greatly improve forecast performance. Bayesian methods have proved popular since the use of prior information offers a formal way of shrinking forecasts. Almost all of the existing literature focusses on VARs where the number of dependent variables is small (typically two or three and rarely more than ten). However, in a recent paper, Banbura, Giannone and Reichlin (2010), hereafter BGR, consider larger Bayesian VARs. They work with what they call a "medium" VAR involving 20 dependent variables and a "large" VAR with 130 dependent variables. Traditionally, researchers working with so many macroeconomic variables have used factor methods (e.g. Stock and Watson, 2002, 2006, Forni, Hallin, Lippi and Reichlin, 2003, Koop and Potter, 2004 and Korobilis, 2009). However, BGR finds that medium and large Bayesian VARs can forecast better than factor methods (at least in their empirical application). Given that VARs have other advantages (e.g. in that impulse responses are easier to interpret), this suggests Bayesian VARs could be a useful addition to the macroeconomic forecaster's toolbox even in cases where the research is working with dozens or hundreds of variables.

BGR uses a natural conjugate variant of the Minnesota prior popularized by Doan, Litterman and Sims, 1984 and Litterman, 1986. The BGR prior shrinks all VAR coefficients towards zero except for coefficients on own lags of each dependent variable. The latter are either set to one (for variables which exhibit substantial persistence) or zero (for variables which do not). Thus, forecasts are shrunk towards a random walk for some variables and towards white noise for others. The degree of shrinkage is controlled by a single scalar hyperparameter. This is potentially an attractive and simple way of doing Bayesian shrinkage in large VARs. However, there are alternative ways of implementing the Minnesota prior which allow for different degrees of shrinkage on coefficients (e.g. coefficients on own lags of a dependent variable can be shrunk to a lesser extent than coefficients on lags of other dependent variables). Such methods are more restrictive in their treatment of the error covariance matrix than BGR's implementation of the Minnesota prior. Nevertheless it is possible that allowing for different degrees of shrinkage provides benefits which outweigh the costs of such restrictiveness. A first purpose of this paper is to investigate this issue.

Furthermore, there are alternative ways of doing shrinkage in Bayesian VARs. One attractive approach is the stochastic search variable selection (SSVS) prior of George, Sun and Ni (2008). A common property of VARs is that they have a great number of parameters, but many of these are unimportant and, thus, shrinkage towards zero (or a constant) is desirable. The SSVS prior allows this to be done in an automatic fashion, with minimal subjective prior information required by the researcher. One purpose of this paper is to investigate how SSVS methods (previously used only with small VARs) work with larger VARs. However, as we shall see, conventional SSVS methods for VARs (which use a non-conjugate VARs) run past current computational limits when working with large VARs. Thus, we only use conventional SSVS methods for medium VARs with up to 20 dependent variables. In order to work with SSVS in larger VARs, we also consider natural conjugate methods for SSVS is VARs. We show how these are computationally feasible with larger VARs and present empirical results using up to 40 
dependent variables.

A third purpose of this paper is to develop methods for combining the Minnesota prior with the SSVS prior. After all, each of them has attractive properties and so it is possible that a combination of the two will improve forecast performance.

Finally, the Bayesian methods used in this paper produce an entire predictive distribution and not merely a point forecast. The previous literature (e.g. BGR and Marcellino, Stock and Watson, 2006) typically focusses on point forecasts, using measures of forecast performance such as mean squared forecast error (MSFE). In this paper, the list of forecast metrics is expanded to include a measure based on the predictive likelihood which involve the entire predictive distribution.

The data set used in this paper is an updated version of that used in Stock and Watson (2008) and is described in the Data Appendix. ${ }^{1}$ The complete data set include 168 variables and runs from 1959Q1 through 2008Q4. Our forecasting exercise finds that Bayesian VAR methods do out-perform factor methods. However, we find no single approach to Bayesian VAR forecasting consistently forecasts best. Roughly speaking, we find that SSVS-based methods work best in cases where relatively low dimensional VARs are adequate, but approaches based on the Minnesota prior work best when medium or large VARs are needed. But there are some important exceptions to this pattern. Furthermore, traditional, simpler implementations of Minnesota priors often out-perform BGR's version of the Minnesota prior. Our results highlight the different ways in which different priors achieve the shrinkage and/or parsimony that is important in achieving good forecast performance with large macroeconomic data sets.

\section{The Econometrics of Bayesian VARs}

We write the VAR in matrix form as:

$$
Y=X A+\varepsilon,
$$

where $Y$ is a $T \times n$ matrix with $t^{\text {th }}$ row given by $y_{t}^{\prime}$ where $y_{t}$ is a vector of $n$ dependent variables, $X$ is a $T \times K$ matrix. In our empirical work $K=(1+p n)$ since each row of contains $p$ lags of each dependent variable and an intercept. That is, the $t^{t h}$ row of $X$ is given by the vector $\left(1, y_{t-1}^{\prime}, \ldots, y_{t-p}^{\prime}\right)$. $A$ is the matrix of coefficients and $\varepsilon$ is a $T \times n$ matrix with $t^{t h}$ row given by $\varepsilon_{t}^{\prime}$. $\varepsilon_{t}$ are independent $N(0, \Sigma)$ errors for $t=1, . ., T$. Define $\alpha=\operatorname{vec}(A)$ which is a vector of $n K$ elements. The dimensionality of $\alpha$ plays a key role in the following discussion. Note that a large VAR with quarterly data might have $n=100$ and $p=4$ in which case $\alpha$ contains over 40,000 elements. With monthly data it would have over 100,000 elements. For a medium VAR, $\alpha$ might have about 1,500 elements with quarterly data. $\Sigma$, too, will be parameter rich, containing $\frac{n(n+1)}{2}$ elements. A typical macroeconomic quarterly data set might have approximately two hundred observations and, hence, the number of coefficients will far exceed the number of observations. Bayesian methods combine likelihood function with prior. It is well-known (e.g. Poirier, 1998) that, even if some parameters are not identified in the likelihood function, under weak conditions the use of a proper prior will lead to a valid posterior density and, thus, Bayesian inference is possible. However, prior information

\footnotetext{
${ }^{1}$ I would like to thank Mark Watson for providing this data.
} 
becomes increasingly important as the number of parameters increases relative to sample size. A theme of this paper is to investigate the role of prior information as it relates to how shrinkage is done.

\subsection{Natural conjugate priors for VARs}

For reasons to be made clear in this sub-section, BGR work with a natural conjugate prior, ${ }^{2}$ despite the fact that there is a well-known drawback with the use of such priors with VARs (see, e.g., Kadiyala and Karlsson, 1997). The natural conjugate prior has the form:

$$
\alpha \mid \Sigma \sim N(\underline{\alpha}, \Sigma \otimes \underline{V})
$$

and

$$
\Sigma^{-1} \sim W\left(\underline{S}^{-1}, \underline{\nu}\right)
$$

where $\underline{\alpha}, \underline{V}, \underline{\nu}$ and $\underline{S}$ are prior hyperparameters and $W\left(\underline{S}^{-1}, \underline{\nu}\right)$ denotes the Wishart distribution with scale $\underline{S}^{-1}$ and degrees of freedom $\underline{\nu}$. For future reference, let $\underline{A}$ be a $K \times n$ matrix defined through the relationship $\underline{\alpha}=\operatorname{vec}(\underline{A})$.

Note that the traditional Minnesota prior is not the same as this natural conjugate prior since the former does not treat $\Sigma$ as a matrix of unknown parameters, but simply replaces $\Sigma$ with an estimate, $\widehat{\Sigma}$. In particular, the traditional Minnesota prior assumes $\Sigma$ to be a diagonal matrix with diagonal elements $s_{i}^{2}$ where $s_{i}^{2}$ is the standard OLS estimate of the error variance in an $\mathrm{AR}(\mathrm{p})$ model for the $i^{\text {th }}$ variable. Sensibly wishing to allow for correlations between the errors, BGR treats $\Sigma$ as an unknown positive definite matrix with $\underline{S}$ chosen in a manner inspired by the Minnesota prior.

Natural conjugate priors can be interpreted as arising from a fictitious prior data set. To be precise, if $\underline{Y}$ and $\underline{X}$ are $(K+n) \times n$ and $(K+n) \times K$, respectively, then we can write the prior hyperparameters as $\underline{\nu}$,

$$
\begin{gathered}
\underline{A}=\left(\underline{X^{\prime}} \underline{X}\right)^{-1} \underline{X^{\prime}} \underline{Y} \\
\underline{S}=(\underline{Y}-\underline{X A})^{\prime}(\underline{Y}-\underline{X A})
\end{gathered}
$$

and

$$
\underline{V}=\left(\underline{X}^{\prime} \underline{X}\right)^{-1}
$$

If we stack the prior and actual data as $\bar{Y}=\left(Y^{\prime}, \underline{Y^{\prime}}\right)^{\prime}$ and $\bar{X}=\left(X^{\prime}, \underline{X}^{\prime}\right)^{\prime}$, it can be shown that the posterior is:

$$
\alpha \mid \Sigma, Y \sim N(\bar{\alpha}, \Sigma \otimes \bar{V})
$$

and

$$
\Sigma^{-1} \mid Y \sim W\left(\bar{S}^{-1}, \bar{\nu}\right)
$$

where

\footnotetext{
${ }^{2}$ Natural conjugate priors are those where the prior, likelihood and posterior come from the same family of distributions.
} 


$$
\begin{gathered}
\bar{V}=\left(\bar{X}^{\prime} \bar{X}\right)^{-1}, \\
\bar{A}=\left(\bar{X}^{\prime} \bar{X}\right)^{-1} \bar{X}^{\prime} \bar{Y} \\
\bar{\alpha}=\operatorname{vec}(\bar{A}), \quad \bar{S}=(\bar{Y}-\overline{X A})^{\prime}(\bar{Y}-\overline{X A})
\end{gathered}
$$

and

$$
\bar{\nu}=T+\underline{\nu} .
$$

The general form for the prior "sample" is

$$
\underline{Y}=\left(\frac{\underline{V}^{-\frac{1}{2}}}{\underline{S}^{\frac{1}{2}}}\right), \underline{X}=\left(\begin{array}{l}
\underline{V}^{-\frac{1}{2}} \\
0_{n \times n K}
\end{array}\right),
$$

where notation such as $\underline{S}^{\frac{1}{2}}$ implies a matrix such that $\left(\underline{S}^{\frac{1}{2}}\right)^{\prime} \underline{S}^{\frac{1}{2}}=\underline{S}$ and $0_{a \times b}$ is an $a \times b$ matrix of zeros.

BGR show how a prior which coincides with the traditional Minnesota prior (except that $\Sigma$ is treated as unknown and a single scalar $\lambda$ is used for shrinkage instead of the two scalars used for shrinkage in the traditional implementation) arises if the fictitious sample is set as:

$$
\underline{Y}=\left(\begin{array}{l}
\frac{\operatorname{diag}\left(\underline{\delta}_{1} s_{1}, ., \underline{\delta}_{n} s_{n}\right)}{\lambda} \\
0_{(n p-n+1) \times n} \\
\operatorname{diag}\left(s_{1}, . ., s_{n}\right)
\end{array}\right), \underline{X}=\left(\begin{array}{ll}
J_{p} \otimes \frac{\operatorname{diag}\left(s_{1}, \ldots, s_{n}\right)}{\lambda} & 0_{n p \times 1} \\
0_{1 \times n p} & v \\
0_{n \times n p} & 0_{n \times 1}
\end{array}\right),
$$

where $J_{p}=\operatorname{diag}(1,2, . ., p)$, $\operatorname{diag}($.$) denotes a diagonal matrix. \underline{\delta}_{i}=1$ if the $i^{\text {th }}$ variable is believed to exhibit substantial persistence (i.e. it ensures shrinkage towards a random walk) and $\underline{\delta}_{i}=0$ if the $i^{\text {th }}$ variable is believed to exhibit little persistence (i.e. it ensures shrinkage towards white noise). The middle row of $\underline{X}$ determines the prior for the intercept. By choosing $v$ to be very small, a relatively noninformative prior for the intercept is obtained. The form of $\underline{Y}$ implies the prior mean for the intercept is zero.

Posterior inference about the VAR coefficients can be carried out using the fact that the marginal posterior (i.e. after integrating out $\Sigma$ ) for $\alpha$ is a multivariate tdistribution. The mean of this t-distribution is $\bar{\alpha}$, its degrees of freedom parameter is $\bar{\nu}$ and its covariance matrix is:

$$
\operatorname{var}(\alpha \mid Y)=\frac{1}{\bar{\nu}-n-1} \bar{S} \otimes \bar{V}
$$

The predictive distribution for $y_{T+1}$ in this model has an analytical form and, in particular, is multivariate-t with $\bar{\nu}$ degrees of freedom. Point forecasts can be based on the predictive mean:

$$
E\left(y_{T+1} \mid Y\right)=\left(x_{T+1} \bar{A}\right)^{\prime} .
$$

The predictive covariance matrix is 


$$
\operatorname{var}\left(y_{T+1} \mid Y\right)=\frac{1}{\bar{\nu}-2}\left[1+x_{T+1} \bar{V} x_{T+1}^{\prime}\right] \bar{S} .
$$

When forecasting more than one period ahead, an analytical formula for the predictive density does not exist. This means that either the direct forecasting method must be used (which turns the problem into one which only involves one step ahead forecasting) or predictive simulation is required. In this paper, we use the direct method.

The use of the natural conjugate prior leads to one large benefit: analytical results are available for Bayesian inference and forecasting, so no posterior simulation is required. For large Bayesian VARs a second benefit exists: the $\Sigma \otimes \bar{V}$ form for the conditional posterior covariance matrix of $\alpha$ in (4) enormously simplifies computation. Note that with this prior, calculating $\bar{V}$ involves inverting a $K \times K$ matrix (see 6) which, even for a large VAR (when $K$ is a few hundreds or, at most, a few thousand) is feasible. To preview one of the crucial econometric issues in the present paper, when working with non-conjugate priors such as the conventional implementation of SSVS, calculating the posterior covariance matrix involves inverting an $n K \times n K$ matrix (e.g. with quarterly data it would involve inverting something like a 40,000 $\times 40,000$ matrix). For medium VARs (e.g. up to $n=20$ ), Bayesian computation with non-conjugate priors is feasible (but very slow), with large VARs it is computationally infeasible. It is this consideration which leads us to investigate the conditionally conjugate implementation of SSVS for VARs discussed below.

However, the natural conjugate prior has a restrictive property which means it has been rarely used in practice. This arises from the fact that the prior covariance of the coefficients in equation $i$ is $\sigma_{i i} \underline{V}$ where $\sigma_{i i}$ is the $(i i)^{t h}$ element of $\Sigma$ (see 2). This implies that the prior variance of the coefficients in any two equations must be proportional to one another, a possibly restrictive feature. The traditional Minnesota prior (which treats $\Sigma$ as fixed) has the property that coefficients on own lags (i.e. in equation $i$ these are lags of the $i^{\text {th }}$ dependent variable) have a larger prior variance (i.e. are shrunk less) than coefficients on other lags (i.e. lags of the dependent variables in other equations). This feature is not possible using the natural conjugate prior and, accordingly, BGR applies the same degree of shrinkage to coefficients on own and other lags. In an ideal world, one may wish to relax such an assumption and this is something we investigate below. But given computational limitations and the inevitable compromises and tradeoffs of empirical work in high-dimensional models, it may be a sensible one to make.

However, it is worth investigating whether having two prior hyperparameters controlling shrinkage $\left(\lambda_{1}\right.$ and $\left.\lambda_{2}\right)$ as in the original Minnesota prior yields forecasting benefits. The cost of this is that we cannot have $\Sigma$ being a general positive definite matrix. We do not present details of posterior inference and forecasting with the traditional Minnesota prior since they are available in many places (see, e.g., Kadiyala and Karlsson, 1997). However, our empirical section of this paper includes results for the original Minnesota prior (which assumes $\Sigma$ to be diagonal and replaces the diagonal elements by OLS estimates based on $n$ individual $\mathrm{AR}(\mathrm{p})$ regressions as described above). We also present results for a modification of this, where the upper-left hand block of $\Sigma$ (corresponding to a reduced set of important variables which are the ones being forecast) is not assumed to be diagonal. Instead it is replaced by the posterior mean based on a VAR using this reduced set of important variables. The remainder of $\Sigma$ is diagonal as in the original Minnesota prior. Our reduced set of important variables 
are the ones labelled "Three Main Variables used in all VARs" in the Data Appendix. This approach allows for correlation between the errors in the most important equations in the VAR. This may represent a good compromise between the two extremes of allowing no correlation between any errors (as in the original Minnesota prior) and the other extreme of allowing for correlation between all of the errors (as in BGR) and running the risks associated with over-parameterization.

\subsection{The Non-conjugate SSVS Prior}

The variant of the Minnesota prior used in BGR has many advantages (e.g. the fact that analytical results exist for posterior and predictive density). However, it does embody some quite extreme prior assumptions. For instance, the huge $[n \times(1+p n)] \times$ $[n \times(1+p n)]$ prior covariance matrix for $\alpha$ has a prior which is parameterized extremely tightly in terms of a single scalar $\lambda$ with most elements simply being set to zero. It is also a data-based prior with $s_{i}^{2}$ being chosen based on preliminary estimation of $\mathrm{AR}(\mathrm{p})$ models for each variable. Furthermore, the prior will take the same form at each point in time in a recursive forecasting exercise and so coefficients will be shrunk in the same way at all points in time. This may be inappropriate if the set of relevant predictors for a dependent variable changes over time, or if the persistence in a dependent variable changes over time. The SSVS prior is an alternative method of achieving shrinkage in VARs, but it does so in a different manner and without so many restrictive assumptions. And the SSVS prior can adapt by including/excluding different explanatory variables as time goes by in a recursive or rolling forecasting exercise.

To explain the main aspect of SSVS, let $\alpha_{j}$ denote the $j^{\text {th }}$ element of $\alpha$. Instead of simply using a prior such as the Minnesota prior, SSVS specifies a hierarchical prior (i.e. a prior expressed in terms of parameters which in turn have a prior of their own) which is a mixture of two Normal distributions:

$$
\alpha_{j} \mid \gamma_{j} \sim\left(1-\gamma_{j}\right) N\left(\underline{\alpha}_{j}, \kappa_{0 j}^{2}\right)+\gamma_{j} N\left(\underline{\alpha}_{j}, \kappa_{1 j}^{2}\right)
$$

where $\gamma_{j}$ is a dummy variable. If $\gamma_{j}$ equals one then $\alpha_{j}$ is drawn from the second Normal and if it equals zero then $\alpha_{j}$ is drawn from the first Normal. The prior is hierarchical since $\gamma_{j}$ is treated as an unknown parameter which is estimated in a databased fashion. The SSVS aspect of this prior arises by choosing the first prior variance, $\kappa_{0 j}^{2}$, to be "small" (so that the coefficient is constrained to be virtually equal to $\underline{\alpha}_{j}$ and the corresponding explanatory variable is effectively excluded from the model if $\underline{\alpha}_{j}=0$ ) and the second prior variance, $\kappa_{1 j}^{2}$, to be "large" (implying a relatively noninformative prior for the corresponding coefficient and the corresponding explanatory variable is included). Traditional implementations of SSVS set $\underline{\alpha}_{j}=0$ for $j=1, \ldots, n \times(1+p n)$ but it is also possible to set appropriate $\underline{\alpha}_{j}=1$ if the researcher wishes to shrink towards a random walk. In Section 3 we describe alternative procedures for choosing $\kappa_{0 j}^{2}$ and $\kappa_{1 j}^{2}$ one of which leads to a prior which is a combination of a conventional SSVS prior with the Minnesota prior.

The SSVS approach can be thought of as automatically selecting a restricted VAR since it can, in a data-based fashion, set $\gamma_{j}=0$ and (to all intents and purposes) delete the corresponding lagged dependent variable form the model. Alternatively, SSVS can be thought of as a way of doing shrinkage since VAR coefficients can be shrunk to zero. 
But, unlike the Minnesota prior, it chooses which coefficients to shrink to zero in a data-based fashion.

SSVS can be used to select a single restricted model (e.g. the researcher can select a restricted VAR which contains only those lagged dependent variables whose coefficients have $\operatorname{Pr}\left(\gamma_{j}=1 \mid y\right)>a$ for some choice of $a$ such as $\left.a=0.5\right)$. Alternatively, if the Markov Chain Monte Carlo (MCMC) algorithm described in the Technical Appendix is simply run and posterior results for the VAR coefficients calculated using the resulting MCMC output, the result will be Bayesian model averaging (BMA). The latter strategy is adopted in our empirical section.

Complete details of the non-conjugate implementation of SSVS are provided in Section 3 and the Technical Appendix. However, to bring out some basic ideas note that the non-conjugate SSVS prior for $\alpha$ can be written as

$$
\alpha \mid \gamma \sim N(\underline{\alpha}, D)
$$

where $\gamma=\left(\gamma_{1}, . ., \gamma_{K n}\right)^{\prime}$ and $D$ is a diagonal matrix with $(j, j)^{t h}$ element given by $d_{j}$ where

$$
d_{j}=\left\{\begin{array}{l}
\kappa_{0 j}^{2} \text { if } \gamma_{j}=0 \\
\kappa_{1 j}^{2} \text { if } \gamma_{j}=1
\end{array} .\right.
$$

For $\gamma$, the SSVS prior posits that each element has a Bernoulli form (independent of the other elements of $\gamma$ ) and, hence, for $j=1, . ., K$, we have

$$
\begin{aligned}
& \operatorname{Pr}\left(\gamma_{j}=1\right)=\underline{q}_{j} \\
& \operatorname{Pr}\left(\gamma_{j}=0\right)=1-\underline{q}_{j} .
\end{aligned}
$$

We set $\underline{q}_{j}=0.5$ for all $j$. This is a natural default choice, implying each coefficient is $a$ priori equally likely to be included as excluded.

Even if we were to assume a Wishart prior for $\Sigma^{-1}$ (which is not done by George, Sun and $\mathrm{Ni}, 2009$ ), this SSVS prior is not natural conjugate (conditional on $\gamma$ ). Analytical results (conditional on $\gamma$ ) do not exist for this model. Thus, MCMC methods must be used.

As a digression, note that George, Sun and Ni (2008) also do SSVS on the offdiagonal elements of $\Sigma$. Given $\Sigma$ is an $n \times n$ matrix, allowing for SSVS shrinkage in $\Sigma$ with VARs is potentially of great use. In our empirical results, when we use a nonconjugate SSVS prior, we do include SSVS shrinkage for $\Sigma$. However, our conjugate SSVS prior (see below) requires $\Sigma^{-1}$ to have a Wishart distribution and, thus, does not allow for SSVS shrinkage for $\Sigma$.

Papers such as George, Sun and Ni (2008), Korobilis (2009) and Jochmann, Koop and Strachan (2009) have found SSVS to be an excellent way of ensuring shrinkage and improving forecasting performance in small VARs. However, the conventional implementation of SSVS faces two computational problems that makes in infeasible in large VARs and very computationally demanding in medium VARs. First, it involves an MCMC algorithm which, in the context of a recursive forecasting exercise, must be repeated many times. Second, the MCMC algorithm requires the calculation of the conditional posterior covariance matrix for $\alpha$. This is:

$$
\operatorname{var}(\alpha \mid Y, \Sigma, \gamma)=\left[\Sigma^{-1} \otimes\left(X^{\prime} X\right)+D^{-1}\right]^{-1}
$$


and, thus, the inversion of a $K n \times K n$ matrix must be done for each MCMC draw. For medium VARs this is slow but feasible, for large VARs it is infeasible. We must look to some simplifications to obtain an SSVS-based method which is suitable for larger VARs and it is to this we now turn.

\subsection{The Conjugate SSVS Prior}

Previously, we have discussed the advantages (i.e. analytical results and easy computation) and disadvantages (i.e. prior variances for coefficients on a particular explanatory variables in all equations are proportional to one another) of the natural conjugate prior. If we use a conjugate SSVS prior we have similar advantages and disadvantages. In this case, the disadvantage manifests itself in the fact that SSVS will include or exclude each explanatory variable from all equations. Unlike with non-conjugate SSVS, it is not possible for an explanatory variable to be excluded from some equations but not others. Furthermore, the nature of the conjugate prior means that we cannot do SSVS on $\Sigma$.

Conjugate prior SSVS methods for the multivariate Normal regression model are developed in Brown, Vannucci and Fearn (1998) and can be adapted for the VAR. Let $\widetilde{\gamma}$ be a vector of dummy variables defined in a similar manner as $\gamma$, except $\widetilde{\gamma}$ is a $K \times 1$ vector (unlike $\gamma$ which is a $K n \times 1$ vector). The natural conjugate prior given in (2) now becomes conditionally conjugate (i.e. it is conjugate conditional on $\widetilde{\gamma}$ ):

$$
\alpha \mid \Sigma, \widetilde{\gamma} \sim N\left(\underline{\alpha}, \Sigma \otimes D_{\gamma}\right)
$$

where $D_{\gamma}$ is a diagonal matrix with $(j, j)^{t h}$ element given by $d_{j}$ where

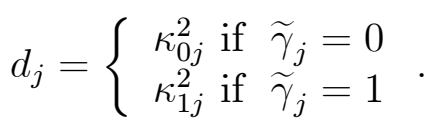

The prior for $\Sigma^{-1}$ remains as given in (3). In our empirical work, we use the same values for $\underline{\alpha}, \underline{\nu}$ and $\underline{S}$ as in our implementation of the BGR's Minnesota prior (see 8). Thus, our prior can be expressed through a fictitious prior sample of:

$$
\underline{Y}=\left(\begin{array}{l}
D_{\gamma}^{-\frac{1}{2}} \underline{A} \\
\operatorname{diag}\left(s_{1}, . ., s_{n}\right)
\end{array}\right), \underline{X}=\left(\begin{array}{c}
D_{\gamma}^{-\frac{1}{2}} \\
0_{n \times K}
\end{array}\right),
$$

where $\underline{A}$ is a matrix of zeros except for the upper left hand block which is $\operatorname{diag}\left(\underline{\delta}_{1}, . ., \underline{\delta}_{n}\right)$.

Bayesian inference using the conditionally conjugate SSVS prior is not as simple as approaches using Minnesota priors due to the addition of $\widetilde{\gamma}$. Conditional on $\widetilde{\gamma}$, the formulae for the posterior for the natural conjugate prior given in Section 2.1 still hold. The conjugacy means that $p(\widetilde{\gamma} \mid Y)$ can easily be evaluated (see the Technical Appendix for the precise formula). However, there are $2^{K}$ possible configurations that $\widetilde{\gamma}$ can take. Unless $K$ is small (which it will not be in our case), exhaustive evaluation of all these possibilities is computationally infeasible. Accordingly, we adopt a posterior simulation strategy based on one suggested in Brown, Vannucci and Fearn (1998). Complete details are provided in the Technical Appendix. 


\section{Forecasting}

\subsection{Data Issues}

The list of 168 variables used in this study, running from 1959Q1 through 2008Q4, is given in the Data Appendix. Following Stock and Watson (2008) and many others, the variables are all transformed to stationarity (usually by differencing or log differencing) as described in the Data Appendix. All data are then standardized by subtracting off the mean and dividing by the standard deviation. Note that this means that our prior means for all coefficients in all approaches are set to zero (instead of setting some prior means to one so as to shrink towards a random walk as would be appropriate if we were working with untransformed variables).

The variables are divided into four groups. The variables in BGR's data set are not identical to those in ours, so we do not match their setup exactly, but the following choices are similar to and motivated by their grouping of variables. The first group contains the three main variables we are interested in forecasting. These are a measure of economic activity (GDP, real GDP), prices (CPI, the consumer price index) and an interest rate (FFR, the Fed funds rate). ${ }^{3}$ The second group contains an additional 17 variables which, added to the three main variables leads to the $n=20$ variables used by BGR in their medium VAR. The choice of these variables is partly motivated the monetary model of Christiano, Eichenbaum and Evans (1999) and partly includes variables found to be useful for forecasting in other studies. The third group contains an additional 20 variables (combined with the other groups, this leads to a larger VAR with $n=40$ variables). These 20 variables have sometimes been found to be useful in forecasting exercises. This group contains most of the remaining aggregate variables in the data set. The remainder of the 168 variables are in a final group. These are mostly the components making up the aggregate variables already included in the other groups.

We thus have small VARs (with $n=3$ ), medium VARs $(n=20)$, medium-large VARs $(n=40)$ and large VARs $(n=168)$. Note that BGR found most of the gains in forecast performance through the use of more variables to have been achieved by using medium VARs, with large VARs forecasting approximately as well as medium VARs. All approaches use four lags of the dependent variables $(p=4)$.

\subsection{Forecast Metrics}

Our rolling and recursive forecast exercises provide us with the predictive density for $y_{\tau+h}$ using data available through time $\tau$ for $h=1$ and 4 . For the rolling forecasts, we use a window of ten years. The predictive density is evaluated for $\tau=\tau_{0}, . ., T-h$ where $\tau_{0}$ is 1969Q4. We use notation where $y_{\tau+h}$ is a random variable we are wishing to forecast (e.g. GDP, CPI or FFR), $y_{\tau+h}^{o}$ is the observed value of the random variable $y_{\tau+h}$ and $p\left(y_{\tau+h} \mid D a t a_{\tau}\right)$ is the predictive density based on information available at time $\tau$.

The most common measure of forecast performance is MSFE where:

\footnotetext{
${ }^{3}$ The transformations used on the data means we are forecasting the difference of log GDP, the second differerence of log CPI and the difference of FFR.
} 


$$
M S F E=\frac{\sum_{\tau=\tau_{0}}^{T-h}\left[y_{\tau+h}^{o}-E\left(y_{\tau+h} \mid D a t a_{\tau}\right)\right]^{2}}{T-h-\tau_{0}+1} .
$$

However, this only uses the point forecasts and ignores the rest of the predictive distribution. For this reason, we also use the predictive likelihood to evaluate forecast performance. Note that a great advantage of predictive likelihoods is that they evaluate the forecasting performance of the entire predictive density. Predictive likelihoods are motivated and described in many places such as Geweke and Amisano (2009). The predictive likelihood is the predictive density for $y_{\tau+h}$ evaluated at the actual outcome $y_{\tau+h}^{o}$. We use the sum of log predictive likelihoods for forecast evaluation:

$$
\sum_{\tau=\tau_{0}}^{T-h} \log \left[p\left(y_{\tau+h}=y_{\tau+h}^{o} \mid D a t a_{\tau}\right)\right] .
$$

\subsection{Forecasting Approaches}

To the three general categories of forecasting methods for Bayesian VARs described above (i.e. Minnesota prior, Non-conjugate SSVS and Conjugate SSVS) we add the category of traditional factor models as a benchmark for comparison. Within each category we have various ways implementations as described in this sub-section.

\subsubsection{Minnesota Priors}

We consider three variants of the Minnesota prior: the first is as in BGR (labelled "Minn. Prior as in BGR" in the tables below). The second is the traditional Minnesota prior (labelled "Minn. Prior $\Sigma$ diagonal"). The third is the traditional Minnesota prior except that the upper left $3 \times 3$ block of $\Sigma$ is not assumed to be diagonal (labelled "Minn. Prior $\Sigma$ not diagonal"). Details of how these are implemented were given in Section 2.1

The Minnesota prior of BGR requires the selection of a single shrinkage parameter, $\lambda$. We choose this in the same manner as BGR. To be precise, an initial set of data is set aside as a training sample (we use all data through 1969Q4 for this purpose). Using this entire training sample we estimate the VARs and then use them for forecasting within this training sample. In medium, medium-large and large VARs, $\lambda$ is chosen so as to yield a fit in this training sample as close as possible to the small VAR for the three main variables being forecast. For the small VAR no shrinkage is done $(\lambda \rightarrow \infty)$.

Fit is defined as:

$$
\text { Fit }_{\lambda n}=\frac{1}{3} \sum_{i=1}^{3} \frac{\operatorname{MSFE}(i, \lambda, n)}{\operatorname{MSFE}(i, 0,3)}
$$

where $M S F E(i, \lambda, n)$ is the MSFE of variable $i$ using shrinkage parameter $\lambda$ in a VAR with $n$ variables. Note that $M S F E(i, 0,3)$ is simply the MSFE produced by the prior in the small VAR which is used to normalize the measure. For the VAR with $n$ variables we choose $\lambda$ to minimize:

$$
\left|F i t_{\lambda n}-F i t_{\infty 3}\right|
$$


Grid search methods are used to solve this minimization problem.

For the other two variants of the Minnesota prior we adopt a similar strategy of matching fit with a small VAR in a training sampler. However, here we have two shrinkage parameters $\left(\lambda_{1}\right.$ which controls shrinkage of coefficients on own lags and $\lambda_{2}$ which controls shrinkage of coefficients on other lags) and do a two-dimensional grid search to minimize the difference in fit between the VAR with $n$ variables and the small VAR with no shrinkage.

\subsubsection{The SSVS Priors}

We implement the non-conjugate SSVS prior approach in two ways. First, we use the "default semi-automatic approach" to prior elicitation suggested by George, Sun and $\mathrm{Ni}$ (2008). This involves setting $\kappa_{0 j}=c_{0} \sqrt{\widehat{\operatorname{var}}\left(\alpha_{j}\right)}$ and $\kappa_{1 j}=c_{1} \sqrt{\widehat{\operatorname{var}}\left(\alpha_{j}\right)}$ where $\widehat{\operatorname{var}}\left(\alpha_{j}\right)$ is an estimate of the variance of the coefficient in an unrestricted VAR. In our case, $\widehat{\operatorname{var}}\left(\alpha_{j}\right)$ is the posterior variance of $\alpha_{j}$ obtained from the corresponding VAR using BGR's prior. The pre-selected constants $c_{0}$ and $c_{1}$ must have $c_{0} \ll c_{1}$ and we set $c_{0}=0.1$ and $c_{1}=10$. Note that this means the semi-automatic prior is a data-based prior. This is labelled "SSVS Non-conj. semi-automatic" in the tables below.

An alternative would be to use the approach just described but choose $\widehat{\operatorname{var}}\left(\alpha_{j}\right)$ in a manner which did not involve the data. A natural choice suggests itself: set $\widehat{\operatorname{var}}\left(\alpha_{j}\right)$ to be the prior variance from BGR's Minnesota prior. We do this, setting $c_{0}=0.1$ and $c_{1}=1$. The results is a prior which has the attractive property that it combines the Minnesota prior with the SSVS prior. That is, if $\gamma_{j}=1$ for $j=1, . ., K$, we obtain a prior which is identical to the one used by BGR. But if $\gamma_{j}=0$ for some $j$, then this prior allows for additional shrinkage beyond that used in the Minnesota prior. And it decides in a data-based fashion whether this extra shrinkage is warranted or not. This is labelled "SSVS Non-conj. plus Minn. Prior" in the tables below.

For the conjugate SSVS prior we use the same two approaches: one a semi-default automatic approach and one which combines the SSVS prior with the Minnesota prior. All details are as above with one exception. Remember that the conjugate SSVS prior either includes or excludes each variable in every equation (rather than including/excluding individual coefficients like the non-conjugate SSVS prior). Hence, we set the $\widehat{\operatorname{var}}\left(\alpha_{j}\right)$ term to be the maximum value for this variance which occurs in any equation. Results for these priors are labelled "SSVS Conjugate semi-automatic" and "SSVS Conjugate plus Minn. Prior" in the tables below.

For the reasons discussed in Section 2.2, it is computationally infeasible to use the non-conjugate SSVS priors with large or even medium-large VARs and, accordingly, we only present results for VARs with $n=3$ and 20. With the conjugate SSVS priors, we present results for VARs with $n=3,20$ and 40, but find $n=168$ to be computationally infeasible and do not present results for the latter case.

\subsubsection{Factor Methods}

As a benchmark to compare our Bayesian VAR approaches, we use factor methods implemented in a standard way. To the small tri-variate VAR we add lags of factors, where the latter are constructed using principal components based on the remaining 165 variables. We include three factors and implement variants where we include one 
and four lags of these factors, respectively. These are labelled "Factor Model $p=1$ " and "Factor Model $p=4$ ", respectively, in the tables below.

\subsection{Results}

Tables 1 through 12 present the results for all our forecasting exercises. The 12 tables arise from our forecasting three variables at two forecasting horizons using recursive and rolling methods. Table 13 provides a summary, listing the single approach which performs best for each of these 12 cases. The upper half of Table 13 uses MSFEs to decide what is "best" while the lower half uses sums of log predictive likelihoods.

There is no one single strong story arising from our empirical results saying, e.g., that one single forecasting method predominates. Our different approaches balance the tension between including more information and ensuring more/different shrinkage in different ways. We cannot say theoretically that one way is better than another, what works will is an empirical matter. In practice we find some approaches doing well in some cases, but not necessarily in others. Nevertheless, a few interesting stories emerge.

Note first that factor methods never lead to the best forecast performance. In all cases, most of our ways of implementing VARs lead to better (and often much better) forecast performance. This confirms the findings made by BGR using a different data set. At a minimum, we have established that working with high-dimensional Bayesian VARs is an alternative worth considering when working with large panels of data.

The results indicate, though, that there is no single approach to VAR forecasting that is predominant. If we take our 12 cases and note that forecast performance can either be evaluated using MSFEs or sums of log predictive likelihoods, we have 24 forecasting "races". In these races, SSVS approaches have 13 "wins" and Minnesota prior approaches win 11 times, a very even split. In terms of VAR dimensionality, large, medium-large and medium VARs each win five times and small VARs win nine times, also a fairly even split. In short, virtually every one of our VAR approaches does well for some variable, forecast horizon or forecasting metric.

Despite the fact that small VARs often forecast well, often we do find that moving away from small VARs does lead to improved forecast performance. That is, reading across any row in Tables 1 through 12 we typically find that the MSFEs or sums of log predictive likelihoods decrease. However, it is worth noting that in most cases, these decreases are small or non-existent when we move beyond $n=20$. This also is consistent with BGRs finding that most of the gains found in VAR forecasting are obtained by using 20 variables and that adding more variables beyond this often yields only slight improvements (or even deterioration) in forecast performance.

However, there are many exceptions to the pattern noted in the preceding paragraph. These exceptions almost invariably occur with the SSVS priors and $h=4$. With the Minnesota priors it is virtually always the case that moving from $n=3$ to $n=20$ improves forecast performance (and often these improvements are considerable). But with $h=4$, it is often the case that small VARs with SSVS priors yield the best forecasting performance. This finding, no doubt, reflects the difficulty of forecasting at longer horizons using the direct method where parsimony is of most particular value. But it also reflects a general pattern in our findings where SSVS methods forecast better than Minnesota priors in small VARs, but that this pattern is not always continued with medium and medium-large VARs. 
When we compare the various implementations of Minnesota priors, we find that BGR's specification often works well. However, in terms of MSFEs, it is often the case that one of the alternative implementations forecasts slightly better. These alternatives are characterized by different degrees of shrinkage for the coefficients on own lags than on other lags, and it does seem that this often improves forecast performance. Our version of the original Minnesota prior which allows for the upper left $3 \times 3$ block of $\Sigma$ to be unrestricted often forecasts quite well. In terms of MSFEs, it appears that the advantages of having a completely unrestricted $\Sigma$ (as in BGR) are relatively small. In terms of sums of log predictive likelihoods, it appears that allowing for an unrestricted $\Sigma$ can occasionally lead to very poor forecast performance. As an example, consider recursively forecasting CPI for $h=1$. In terms of MSFEs, the best forecasting method uses a variant of the original Minnesota prior with a 20-variate VAR. The MSFE is 0.2664. If we consider large VARs with $n=168$, the MSFEs are only slightly higher (0.2834 for the original Minnesota prior and 0.3309 for BGR's prior). However, with these large VARs the sum of log predictive likelihoods is vastly different between the original Minnesota prior (-184.78) and BGR's prior (-322.27). To shed more light on this case, Figures 1 and 2 plots the cumulative sum of log predictive likelihoods and cumulative sum of squared forecast errors, respectively, for these two priors. The cumulative sum of squared forecast errors for these two approaches track each other fairly closely, with the exception of the early 1980s. However, the cumulative sum of log predictive likelihoods are much more different, with the two lines diverging substantially in the period 1975-1985 and again at the end of the sample. This shows that the point forecasts of these two approaches are similar to one another. However, other features of the predictive density are quite different. In this case, what is happening is that BGR's approach tends to yield an unnecessarily disperse predictive distribution due to its need to estimate so many more parameters (i.e. in the BGR approach $\Sigma$ contains $\frac{n(n+1)}{2}$ parameters to be estimated, whereas the original Minnesota prior only has $n$ parameters in $\Sigma$ and these are replaced by simple estimates). Even if the mean of the predictive density provides a good point forecast, an unnecessarily large predictive standard deviation mean that the predictive likelihood evaluated at the outcome will be lower than a predictive without such a large standard deviation. When looking at large VARs (particularly using BGR's prior), we often find this pattern of good MSFEs but poor sums of log predictive likelihoods. A related finding is that small VARs tend to forecast particularly well when we use sums of log predictive likelihoods to evaluate forecast performance, but there is less evidence of this when using MSFEs. By focussing solely on MSFEs, the researcher would miss important empirical findings such as these.

When we compare various implementations of the SSVS priors, few strong patterns emerge. The non-conjugate SSVS prior often forecasts slightly better than the conjugate variant. Using the Minnesota prior to calibrate the prior for the SSVS approach often improves forecast performance. But there are many exceptions to both of these statements.

If we compare recursive to rolling forecasts, we do not find any substantial and consistent differences in forecast performance if we looks at MSFEs. In terms of sums of log predictive likelihoods, more differences appear. However these differences are not consistent in the sense that we cannot say recursive methods are always better than rolling, or vice versa. 


\begin{tabular}{|c|c|c|c|c|}
\hline \multicolumn{5}{|c|}{$\begin{array}{l}\text { Table 1: GDP Forecasting for } h=1 \\
\text { MSFEs as Proportion of Random walk MSFEs } \\
\text { Sums of log predictive likelihoods in parentheses }\end{array}$} \\
\hline & $n=3$ & $n=20$ & $n=40$ & $n=168$ \\
\hline $\begin{array}{l}\text { Minn. Prior } \\
\text { as in BGR }\end{array}$ & $\begin{array}{l}0.6504 \\
(-206.37)\end{array}$ & $\begin{array}{l}0.5552 \\
(-192.29)\end{array}$ & $\begin{array}{l}0.5084 \\
(-186.60)\end{array}$ & $\begin{array}{l}0.5225 \\
(-223.78)\end{array}$ \\
\hline $\begin{array}{l}\text { Minn. Prior } \\
\Sigma \text { diagonal }\end{array}$ & $\begin{array}{l}0.7065 \\
(-211.85)\end{array}$ & $\begin{array}{l}0.5774 \\
(-204.84)\end{array}$ & $\begin{array}{l}0.6381 \\
(-205.52)\end{array}$ & $\begin{array}{l}0.5631 \\
(-202.39)\end{array}$ \\
\hline $\begin{array}{l}\text { Minn. Prior } \\
\Sigma \text { not diagonal }\end{array}$ & $\begin{array}{l}0.7065 \\
(-205.97)\end{array}$ & $\begin{array}{l}0.5489 \\
(-195.40)\end{array}$ & $\begin{array}{l}0.5402 \\
(-193.49)\end{array}$ & $\begin{array}{l}0.5305 \\
(-192.81)\end{array}$ \\
\hline $\begin{array}{l}\text { SSVS Conjugate } \\
\text { semi-automatic }\end{array}$ & $\begin{array}{l}0.6338 \\
(-200.66)\end{array}$ & $\begin{array}{l}0.6776 \\
(-199.90)\end{array}$ & $\begin{array}{l}0.6983 \\
(-197.66)\end{array}$ & n.a. \\
\hline $\begin{array}{l}\text { SSVS Conjugate } \\
\text { plus Minn. Prior }\end{array}$ & $\begin{array}{l}0.6062 \\
(-198.77)\end{array}$ & $\begin{array}{l}0.5577 \\
(-192.53)\end{array}$ & $\begin{array}{l}0.5368 \\
(-192.44)\end{array}$ & n.a. \\
\hline $\begin{array}{l}\text { SSVS Non-conj. } \\
\text { semi-automatic }\end{array}$ & $\begin{array}{l}0.6061 \\
(-198.40)\end{array}$ & $\begin{array}{l}0.6407 \\
(-205.12)\end{array}$ & n.a. & n.a. \\
\hline $\begin{array}{l}\text { SSVS Non-conj. } \\
\text { plus Minn. Prior }\end{array}$ & $\begin{array}{l}0.6975 \\
(-204.71)\end{array}$ & $\begin{array}{l}0.6466 \\
(-203.92)\end{array}$ & n.a. & n.a. \\
\hline $\begin{array}{l}\text { Factor Model } \\
p=1\end{array}$ & n.a. & n.a. & n.a. & $\begin{array}{l}0.6441 \\
(-195.10)\end{array}$ \\
\hline $\begin{array}{l}\text { Factor Model } \\
p=4\end{array}$ & n.a. & n.a. & n.a. & $\begin{array}{l}0.7657 \\
(-207.67)\end{array}$ \\
\hline \multicolumn{5}{|c|}{$\begin{array}{l}\text { Table 2: CPI Forecasting for } h=1 \\
\text { MSFEs as Proportion of Random walk MSFEs } \\
\text { Sums of log predictive likelihoods in parentheses }\end{array}$} \\
\hline & $n=3$ & $n=20$ & $n=40$ & $n=168$ \\
\hline $\begin{array}{l}\text { Minn. Prior } \\
\text { as in BGR }\end{array}$ & $\begin{array}{l}0.3471 \\
(-201.23)\end{array}$ & $\begin{array}{l}0.3029 \\
(-195.90)\end{array}$ & $\begin{array}{l}0.3172 \\
(-210.09)\end{array}$ & $\begin{array}{l}0.3309 \\
(-322.27)\end{array}$ \\
\hline $\begin{array}{l}\text { Minn. Prior } \\
\Sigma \text { diagonal }\end{array}$ & $\begin{array}{l}0.3317 \\
(-190.85)\end{array}$ & $\begin{array}{l}0.2756 \\
(-182.18)\end{array}$ & $\begin{array}{l}0.3252 \\
(-200.55)\end{array}$ & $\begin{array}{l}0.2834 \\
(-184.78)\end{array}$ \\
\hline $\begin{array}{l}\text { Minn. Prior } \\
\Sigma \text { not diagonal }\end{array}$ & $\begin{array}{l}0.3317 \\
(-203.95)\end{array}$ & $\begin{array}{l}0.2664 \\
(-184.06)\end{array}$ & $\begin{array}{l}0.2718 \\
(-188.27)\end{array}$ & $\begin{array}{l}0.3019 \\
(-197.45)\end{array}$ \\
\hline $\begin{array}{l}\text { SSVS Conjugate } \\
\text { semi-automatic }\end{array}$ & $\begin{array}{l}0.3138 \\
(-187.82)\end{array}$ & $\begin{array}{l}0.2724 \\
(-191.15)\end{array}$ & $\begin{array}{l}0.3061 \\
(-197.66)\end{array}$ & n.a. \\
\hline $\begin{array}{l}\text { SSVS Conjugate } \\
\text { plus Minn. Prior }\end{array}$ & $\begin{array}{l}0.3086 \\
(-186.70)\end{array}$ & $\begin{array}{l}0.3088 \\
(-197.64)\end{array}$ & $\begin{array}{l}0.3601 \\
(-222.30)\end{array}$ & n.a. \\
\hline $\begin{array}{l}\text { SSVS Non-conj. } \\
\text { semi-automatic }\end{array}$ & $\begin{array}{l}0.3197 \\
(-193.92)\end{array}$ & $\begin{array}{l}0.3161 \\
(-196.47)\end{array}$ & n.a. & n.a. \\
\hline $\begin{array}{l}\text { SSVS Non-conj. } \\
\text { plus Minn. Prior }\end{array}$ & $\begin{array}{l}0.3252 \\
(-191.45)\end{array}$ & $\begin{array}{l}0.2910 \\
(-187.58)\end{array}$ & n.a. & n.a. \\
\hline $\begin{array}{l}\text { Factor Model } \\
p=1\end{array}$ & n.a. & n.a. & n.a. & $\begin{array}{l}0.3133 \\
(-191.83)\end{array}$ \\
\hline $\begin{array}{l}\text { Factor Model } \\
p=4\end{array}$ & n.a. & n.a. & n.a. & $\begin{array}{l}0.3281 \\
(-209.58) \\
\end{array}$ \\
\hline
\end{tabular}




\begin{tabular}{|c|c|c|c|c|}
\hline \multicolumn{5}{|c|}{$\begin{array}{l}\text { Table 3: FFR Forecasting for } h=1 \\
\text { MSFEs as Proportion of Random walk MSFEs } \\
\text { Sums of log predictive likelihoods in parentheses }\end{array}$} \\
\hline & $n=3$ & $n=20$ & $n=40$ & $n=168$ \\
\hline $\begin{array}{l}\text { Minn. Prior } \\
\text { as in BGR }\end{array}$ & $\begin{array}{l}0.6192 \\
(-238.40)\end{array}$ & $\begin{array}{l}0.5136 \\
(-229.14)\end{array}$ & $\begin{array}{l}0.5084 \\
(-243.71)\end{array}$ & $\begin{array}{l}0.5224 \\
(-266.66)\end{array}$ \\
\hline $\begin{array}{l}\text { Minn. Prior } \\
\Sigma \text { diagonal }\end{array}$ & $\begin{array}{l}0.8351 \\
(-247.02)\end{array}$ & $\begin{array}{l}0.5355 \\
(-238.79)\end{array}$ & $\begin{array}{l}0.6218 \\
(-263.05)\end{array}$ & $\begin{array}{l}0.5532 \\
(-239.84)\end{array}$ \\
\hline $\begin{array}{l}\text { Minn. Prior } \\
\Sigma \text { not diagonal }\end{array}$ & $\begin{array}{l}0.8351 \\
(-267.29)\end{array}$ & $\begin{array}{l}0.5164 \\
(-249.09)\end{array}$ & $\begin{array}{l}0.5530 \\
(-249.49)\end{array}$ & $\begin{array}{l}0.5223 \\
(-258.28)\end{array}$ \\
\hline $\begin{array}{l}\text { SSVS Conjugate } \\
\text { semi-automatic }\end{array}$ & $\begin{array}{l}0.7944 \\
(-247.25)\end{array}$ & $\begin{array}{l}0.6329 \\
(-245.25)\end{array}$ & $\begin{array}{l}0.5936 \\
(-256.02)\end{array}$ & n.a. \\
\hline $\begin{array}{l}\text { SSVS Conjugate } \\
\text { plus Minn. Prior }\end{array}$ & $\begin{array}{l}0.7554 \\
(-243.16)\end{array}$ & $\begin{array}{l}0.5134 \\
(-228.54)\end{array}$ & $\begin{array}{l}0.5354 \\
(-251.98)\end{array}$ & n.a. \\
\hline $\begin{array}{l}\text { SSVS Non-conj. } \\
\text { semi-automatic }\end{array}$ & $\begin{array}{l}0.8439 \\
(-252.43)\end{array}$ & $\begin{array}{l}0.5790 \\
(-237.16)\end{array}$ & n.a. & n.a. \\
\hline $\begin{array}{l}\text { SSVS Non-conj. } \\
\text { plus Minn. Prior }\end{array}$ & $\begin{array}{l}0.7436 \\
(-252.68)\end{array}$ & $\begin{array}{l}0.5431 \\
(-228.86)\end{array}$ & n.a. & n.a. \\
\hline $\begin{array}{l}\text { Factor Model } \\
p=1\end{array}$ & n.a. & n.a. & n.a. & $\begin{array}{l}0.7360 \\
(-232.66)\end{array}$ \\
\hline $\begin{array}{l}\text { Factor Model } \\
p=4\end{array}$ & n.a. & n.a. & n.a. & $\begin{array}{l}0.7466 \\
(-237.99)\end{array}$ \\
\hline \multicolumn{5}{|c|}{$\begin{array}{l}\text { Table 4: GDP Forecasting for } h=4 \\
\text { MSFEs as Proportion of Random walk MSFEs } \\
\text { Sums of log predictive likelihoods in parentheses }\end{array}$} \\
\hline & $n=3$ & $n=20$ & $n=40$ & $n=168$ \\
\hline $\begin{array}{l}\text { Minn. Prior } \\
\text { as in BGR }\end{array}$ & $\begin{array}{l}0.7437 \\
(-220.57)\end{array}$ & $\begin{array}{l}0.6094 \\
(-214.71)\end{array}$ & $\begin{array}{l}0.5717 \\
(-214.38)\end{array}$ & $\begin{array}{l}0.5420 \\
(-277.46)\end{array}$ \\
\hline $\begin{array}{l}\text { Minn. Prior } \\
\Sigma \text { diagonal }\end{array}$ & $\begin{array}{l}0.7437 \\
(-219.25)\end{array}$ & $\begin{array}{l}0.6100 \\
(-214.02)\end{array}$ & $\begin{array}{l}0.5728 \\
(-210.99)\end{array}$ & $\begin{array}{l}0.5656 \\
(-210.06)\end{array}$ \\
\hline $\begin{array}{l}\text { Minn. Prior } \\
\Sigma \text { not diagonal }\end{array}$ & $\begin{array}{l}0.7437 \\
(-220.58)\end{array}$ & $\begin{array}{l}0.6214 \\
(-213.28)\end{array}$ & $\begin{array}{l}0.5831 \\
(-209.50)\end{array}$ & $\begin{array}{l}0.5780 \\
(-209.37)\end{array}$ \\
\hline $\begin{array}{l}\text { SSVS Conjugate } \\
\text { semi-automatic }\end{array}$ & $\begin{array}{l}0.6129 \\
(-211.36)\end{array}$ & $\begin{array}{l}0.6473 \\
(-212.35)\end{array}$ & $\begin{array}{l}0.8881 \\
(-239.87)\end{array}$ & n.a. \\
\hline $\begin{array}{l}\text { SSVS Conjugate } \\
\text { plus Minn. Prior }\end{array}$ & $\begin{array}{l}0.8404 \\
(-222.91)\end{array}$ & $\begin{array}{l}0.8357 \\
(-219.64)\end{array}$ & $\begin{array}{l}0.6387 \\
(-222.50)\end{array}$ & n.a. \\
\hline $\begin{array}{l}\text { SSVS Non-conj. } \\
\text { semi-automatic }\end{array}$ & $\begin{array}{l}0.6147 \\
(-207.80)\end{array}$ & $\begin{array}{l}0.7535 \\
(-293.21)\end{array}$ & n.a. & n.a. \\
\hline $\begin{array}{l}\text { SSVS Non-conj. } \\
\text { plus Minn. Prior }\end{array}$ & $\begin{array}{l}0.8438 \\
(-221.57)\end{array}$ & $\begin{array}{l}0.6670 \\
(-219.01)\end{array}$ & n.a. & n.a. \\
\hline $\begin{array}{l}\text { Factor Model } \\
p=1\end{array}$ & n.a. & n.a. & n.a. & $\begin{array}{l}0.7662 \\
(-223.24)\end{array}$ \\
\hline $\begin{array}{l}\text { Factor Model } \\
p=4\end{array}$ & n.a. & n.a. & n.a. & $\begin{array}{l}0.9396 \\
(-240.50) \\
\end{array}$ \\
\hline
\end{tabular}




\begin{tabular}{|c|c|c|c|c|}
\hline \multicolumn{5}{|c|}{$\begin{array}{l}\text { Table 5: CPI Forecasting for } h=4 \\
\text { MSFEs as Proportion of Random walk MSFEs } \\
\text { Sums of log predictive likelihoods in parentheses }\end{array}$} \\
\hline & $n=3$ & $n=20$ & $n=40$ & $n=168$ \\
\hline $\begin{array}{l}\text { Minn. Prior } \\
\text { as in BGR }\end{array}$ & $\begin{array}{l}0.5254 \\
(-209.51)\end{array}$ & $\begin{array}{l}0.5217 \\
(-219.35)\end{array}$ & $\begin{array}{l}0.5246 \\
(-235.65)\end{array}$ & $\begin{array}{l}0.5044 \\
(-262.55)\end{array}$ \\
\hline $\begin{array}{l}\text { Minn. Prior } \\
\Sigma \text { diagonal }\end{array}$ & $\begin{array}{l}0.5254 \\
(-216.43)\end{array}$ & $\begin{array}{l}0.5191 \\
(-217.60)\end{array}$ & $\begin{array}{l}0.5207 \\
(-218.45)\end{array}$ & $\begin{array}{l}0.5124 \\
(-216.64)\end{array}$ \\
\hline $\begin{array}{l}\text { Minn. Prior } \\
\Sigma \text { not diagonal }\end{array}$ & $\begin{array}{l}0.5254 \\
(-214.64)\end{array}$ & $\begin{array}{l}0.5203 \\
(-216.07)\end{array}$ & $\begin{array}{l}0.5214 \\
(-217.57)\end{array}$ & $\begin{array}{l}0.5197 \\
(-217.14)\end{array}$ \\
\hline $\begin{array}{l}\text { SSVS Conjugate } \\
\text { semi-automatic }\end{array}$ & $\begin{array}{l}0.4990 \\
(-211.36)\end{array}$ & $\begin{array}{l}0.6042 \\
(-225.02)\end{array}$ & $\begin{array}{l}0.6847 \\
(-253.84)\end{array}$ & n.a. \\
\hline $\begin{array}{l}\text { SSVS Conjugate } \\
\text { plus Minn. Prior }\end{array}$ & $\begin{array}{l}0.4759 \\
(-199.86)\end{array}$ & $\begin{array}{l}0.7031 \\
(-246.64)\end{array}$ & $\begin{array}{l}0.4853 \\
(-220.44)\end{array}$ & n.a. \\
\hline $\begin{array}{l}\text { SSVS Non-conj. } \\
\text { semi-automatic }\end{array}$ & $\begin{array}{l}0.5010 \\
(-208.26)\end{array}$ & $\begin{array}{l}0.7723 \\
(-226.36)\end{array}$ & n.a. & n.a. \\
\hline $\begin{array}{l}\text { SSVS Non-conj. } \\
\text { plus Minn. Prior }\end{array}$ & $\begin{array}{l}0.4683 \\
(-194.39)\end{array}$ & $\begin{array}{l}0.4883 \\
(-201.62)\end{array}$ & n.a. & n.a. \\
\hline $\begin{array}{l}\text { Factor Model } \\
p=1\end{array}$ & n.a. & n.a. & n.a. & $\begin{array}{l}0.5608 \\
(-214.72)\end{array}$ \\
\hline $\begin{array}{l}\text { Factor Model } \\
p=4\end{array}$ & n.a. & n.a. & n.a. & $\begin{array}{l}0.6258 \\
(-228.84)\end{array}$ \\
\hline \multicolumn{5}{|c|}{$\begin{array}{l}\text { Table 6: FFR Forecasting for } h=4 \\
\text { MSFEs as Proportion of Random walk MSFEs } \\
\text { Sums of log predictive likelihoods in parentheses }\end{array}$} \\
\hline & $n=3$ & $n=20$ & $n=40$ & $n=168$ \\
\hline $\begin{array}{l}\text { Minn. Prior } \\
\text { as in BGR }\end{array}$ & $\begin{array}{l}0.6679 \\
(-243.31)\end{array}$ & $\begin{array}{l}0.5868 \\
(-249.63)\end{array}$ & $\begin{array}{l}0.5670 \\
(-264.80)\end{array}$ & $\begin{array}{l}0.5717 \\
(-319.40)\end{array}$ \\
\hline $\begin{array}{l}\text { Minn. Prior } \\
\Sigma \text { diagonal }\end{array}$ & $\begin{array}{l}0.6679 \\
(-281.95)\end{array}$ & $\begin{array}{l}0.6075 \\
(-278.11)\end{array}$ & $\begin{array}{l}0.5946 \\
(-273.70)\end{array}$ & $\begin{array}{l}0.6379 \\
(-281.92)\end{array}$ \\
\hline $\begin{array}{l}\text { Minn. Prior } \\
\Sigma \text { not diagonal }\end{array}$ & $\begin{array}{l}0.6679 \\
(-246.90)\end{array}$ & $\begin{array}{l}0.5882 \\
(-244.77)\end{array}$ & $\begin{array}{l}0.5894 \\
(-240.50)\end{array}$ & $\begin{array}{l}0.6362 \\
(-245.34)\end{array}$ \\
\hline $\begin{array}{l}\text { SSVS Conjugate } \\
\text { semi-automatic }\end{array}$ & $\begin{array}{l}0.5508 \\
(-236.00)\end{array}$ & $\begin{array}{l}0.5873 \\
(-249.46)\end{array}$ & $\begin{array}{l}0.7408 \\
(-273.60)\end{array}$ & n.a. \\
\hline $\begin{array}{l}\text { SSVS Conjugate } \\
\text { plus Minn. Prior }\end{array}$ & $\begin{array}{l}0.6259 \\
(-235.57)\end{array}$ & $\begin{array}{l}0.6716 \\
(-258.47)\end{array}$ & $\begin{array}{l}0.5370 \\
(-255.89)\end{array}$ & n.a. \\
\hline $\begin{array}{l}\text { SSVS Non-conj. } \\
\text { semi-automatic }\end{array}$ & $\begin{array}{l}0.5265 \\
(-231.16)\end{array}$ & $\begin{array}{l}0.8811 \\
(-268.06)\end{array}$ & n.a. & n.a. \\
\hline $\begin{array}{l}\text { SSVS Non-conj. } \\
\text { plus Minn. Prior }\end{array}$ & $\begin{array}{l}0.6184 \\
(-228.80)\end{array}$ & $\begin{array}{l}0.5282 \\
(-233.67)\end{array}$ & n.a. & n.a. \\
\hline $\begin{array}{l}\text { Factor Model } \\
p=1\end{array}$ & n.a. & n.a. & n.a. & $\begin{array}{l}0.7027 \\
(-244.52)\end{array}$ \\
\hline $\begin{array}{l}\text { Factor Model } \\
p=4\end{array}$ & n.a. & n.a. & n.a. & $\begin{array}{l}0.7185 \\
(-249.04) \\
\end{array}$ \\
\hline
\end{tabular}




\begin{tabular}{|c|c|c|c|c|}
\hline \multicolumn{5}{|c|}{$\begin{array}{l}\text { Table 7: Rolling GDP Forecasting for } h=1 \\
\text { MSFEs as Proportion of Random walk MSFEs } \\
\text { Sums of log predictive likelihoods in parentheses }\end{array}$} \\
\hline & $n=3$ & $n=20$ & $n=40$ & $n=168$ \\
\hline $\begin{array}{l}\text { Minn. Prior } \\
\text { as in BGR }\end{array}$ & $\begin{array}{l}0.8927 \\
(-227.38)\end{array}$ & $\begin{array}{l}0.5842 \\
(-190.51)\end{array}$ & $\begin{array}{l}0.5304 \\
(-202.32)\end{array}$ & $\begin{array}{l}0.5639 \\
(-460.63)\end{array}$ \\
\hline $\begin{array}{l}\text { Minn. Prior } \\
\Sigma \text { diagonal }\end{array}$ & $\begin{array}{l}0.8927 \\
(-231.88)\end{array}$ & $\begin{array}{l}0.6112 \\
(-194.04)\end{array}$ & $\begin{array}{l}0.5845 \\
(-193.66)\end{array}$ & $\begin{array}{l}0.6064 \\
(-192.87)\end{array}$ \\
\hline $\begin{array}{l}\text { Minn. Prior } \\
\Sigma \text { not diagonal }\end{array}$ & $\begin{array}{l}0.8927 \\
(-234.99)\end{array}$ & $\begin{array}{l}0.6092 \\
(-192.12)\end{array}$ & $\begin{array}{l}0.5856 \\
(-191.01)\end{array}$ & $\begin{array}{l}0.5669 \\
(-187.08)\end{array}$ \\
\hline $\begin{array}{l}\text { SSVS Conjugate } \\
\text { semi-automatic }\end{array}$ & $\begin{array}{l}0.6762 \\
(-202.91)\end{array}$ & $\begin{array}{l}0.8061 \\
(-209.44)\end{array}$ & $\begin{array}{l}0.6267 \\
(-212.25)\end{array}$ & n.a. \\
\hline $\begin{array}{l}\text { SSVS Conjugate } \\
\text { plus Minn. Prior }\end{array}$ & $\begin{array}{l}0.8866 \\
(-226.76)\end{array}$ & $\begin{array}{l}0.5916 \\
(-191.41)\end{array}$ & $\begin{array}{l}0.5287 \\
(-202.09)\end{array}$ & n.a. \\
\hline $\begin{array}{l}\text { SSVS Non-conj. } \\
\text { semi-automatic }\end{array}$ & $\begin{array}{l}0.7046 \\
(-201.60)\end{array}$ & $\begin{array}{l}0.8780 \\
(-234.25)\end{array}$ & n.a. & n.a. \\
\hline $\begin{array}{l}\text { SSVS Non-conj. } \\
\text { plus Minn. Prior }\end{array}$ & $\begin{array}{l}0.8797 \\
(-221.53)\end{array}$ & $\begin{array}{l}0.6766 \\
(-197.85)\end{array}$ & n.a. & n.a. \\
\hline $\begin{array}{l}\text { Factor Model } \\
p=1\end{array}$ & n.a. & n.a. & n.a. & $\begin{array}{l}1.0291 \\
(-239.63)\end{array}$ \\
\hline $\begin{array}{l}\text { Factor Model } \\
p=4\end{array}$ & n.a. & n.a. & n.a. & $\begin{array}{l}3.1015 \\
(-375.01)\end{array}$ \\
\hline
\end{tabular}




\begin{tabular}{|c|c|c|c|c|}
\hline \multicolumn{5}{|c|}{$\begin{array}{l}\text { Table 8: Rolling CPI Forecasting for } h=1 \\
\text { MSFEs as Proportion of Random walk MSFEs } \\
\text { Sums of log predictive likelihoods in parentheses }\end{array}$} \\
\hline & $n=3$ & $n=20$ & $n=40$ & $n=168$ \\
\hline $\begin{array}{l}\text { Minn. Prior } \\
\text { as in BGR }\end{array}$ & $\begin{array}{l}0.4452 \\
(-217.17)\end{array}$ & $\begin{array}{l}0.3414 \\
(-209.19)\end{array}$ & $\begin{array}{l}0.3584 \\
(-243.04)\end{array}$ & $\begin{array}{l}0.3709 \\
(-559.89)\end{array}$ \\
\hline $\begin{array}{l}\text { Minn. Prior } \\
\Sigma \text { diagonal }\end{array}$ & $\begin{array}{l}0.4452 \\
(-217.43)\end{array}$ & $\begin{array}{l}0.3048 \\
(-193.00)\end{array}$ & $\begin{array}{l}0.2979 \\
(-192.04)\end{array}$ & $\begin{array}{l}0.3099 \\
(-195.38)\end{array}$ \\
\hline $\begin{array}{l}\text { Minn. Prior } \\
\Sigma \text { not diagonal }\end{array}$ & $\begin{array}{l}0.4452 \\
(-234.08)\end{array}$ & $\begin{array}{l}0.3068 \\
(-202.38)\end{array}$ & $\begin{array}{l}0.3038 \\
(-202.50)\end{array}$ & $\begin{array}{l}0.3503 \\
(-217.58)\end{array}$ \\
\hline $\begin{array}{l}\text { SSVS Conjugate } \\
\text { semi-automatic }\end{array}$ & $\begin{array}{l}0.3843 \\
(-207.34)\end{array}$ & $\begin{array}{l}0.3808 \\
(-231.81)\end{array}$ & $\begin{array}{l}0.3886 \\
(-261.44)\end{array}$ & n.a. \\
\hline $\begin{array}{l}\text { SSVS Conjugate } \\
\text { plus Minn. Prior }\end{array}$ & $\begin{array}{l}0.4415 \\
(-216.36)\end{array}$ & $\begin{array}{l}0.3516 \\
(-212.11)\end{array}$ & $\begin{array}{l}0.3650 \\
(-245.59)\end{array}$ & n.a. \\
\hline $\begin{array}{l}\text { SSVS Non-conj. } \\
\text { semi-automatic }\end{array}$ & $\begin{array}{l}0.3668 \\
(-191.97)\end{array}$ & $\begin{array}{l}0.4674 \\
(-235.98)\end{array}$ & n.a. & n.a. \\
\hline $\begin{array}{l}\text { SSVS Non-conj. } \\
\text { plus Minn. Prior }\end{array}$ & $\begin{array}{l}0.4344 \\
(-198.53)\end{array}$ & $\begin{array}{l}0.3402 \\
(-195.22)\end{array}$ & n.a. & n.a. \\
\hline $\begin{array}{l}\text { Factor Model } \\
p=1\end{array}$ & n.a. & n.a. & n.a. & $\begin{array}{l}0.5591 \\
(-234.66)\end{array}$ \\
\hline $\begin{array}{l}\text { Factor Model } \\
p=4\end{array}$ & n.a. & n.a. & n.a. & $\begin{array}{l}1.3334 \\
(-434.43)\end{array}$ \\
\hline \multicolumn{5}{|c|}{$\begin{array}{l}\text { Table 9: Rolling FFR Forecasting for } h=1 \\
\text { MSFEs as Proportion of Random walk MSFEs } \\
\text { Sums of log predictive likelihoods in parentheses }\end{array}$} \\
\hline & $n=3$ & $n=20$ & $n=40$ & $n=168$ \\
\hline $\begin{array}{l}\text { Minn. Prior } \\
\text { as in BGR }\end{array}$ & $\begin{array}{l}1.1119 \\
(-218.83)\end{array}$ & $\begin{array}{l}0.5071 \\
(-177.41)\end{array}$ & $\begin{array}{l}0.5183 \\
(-197.27)\end{array}$ & $\begin{array}{l}0.5468 \\
(-460.62)\end{array}$ \\
\hline $\begin{array}{l}\text { Minn. Prior } \\
\Sigma \text { diagonal }\end{array}$ & $\begin{array}{l}1.1119 \\
(-221.50)\end{array}$ & $\begin{array}{l}0.5228 \\
(-181.74)\end{array}$ & $\begin{array}{l}0.5460 \\
(-181.91)\end{array}$ & $\begin{array}{l}0.5516 \\
(-186.36)\end{array}$ \\
\hline $\begin{array}{l}\text { Minn. Prior } \\
\Sigma \text { not diagonal }\end{array}$ & $\begin{array}{l}1.1119 \\
(-231.86)\end{array}$ & $\begin{array}{l}0.5260 \\
(-185.88)\end{array}$ & $\begin{array}{l}0.5414 \\
(-185.11)\end{array}$ & $\begin{array}{l}0.5410 \\
(-198.86)\end{array}$ \\
\hline $\begin{array}{l}\text { SSVS Conjugate } \\
\text { semi-automatic }\end{array}$ & $\begin{array}{l}0.7415 \\
(-190.00)\end{array}$ & $\begin{array}{l}0.6324 \\
(-175.82)\end{array}$ & $\begin{array}{l}0.5933 \\
(-209.07)\end{array}$ & n.a. \\
\hline $\begin{array}{l}\text { SSVS Conjugate } \\
\text { plus Minn. Prior }\end{array}$ & $\begin{array}{l}1.1070 \\
(-218.19)\end{array}$ & $\begin{array}{l}0.5069 \\
(-179.18)\end{array}$ & $\begin{array}{l}0.5255 \\
(-201.34)\end{array}$ & n.a. \\
\hline $\begin{array}{l}\text { SSVS Non-conj. } \\
\text { semi-automatic }\end{array}$ & $\begin{array}{l}0.8035 \\
(-191.48)\end{array}$ & $\begin{array}{l}0.7348 \\
(-213.03)\end{array}$ & n.a. & n.a. \\
\hline $\begin{array}{l}\text { SSVS Non-conj. } \\
\text { plus Minn. Prior }\end{array}$ & $\begin{array}{l}1.1119 \\
(-210.90)\end{array}$ & $\begin{array}{l}0.5239 \\
(-177.18)\end{array}$ & n.a. & n.a. \\
\hline $\begin{array}{l}\text { Factor Model } \\
p=1\end{array}$ & n.a. & n.a. & n.a. & $\begin{array}{l}1.2240 \\
(-238.92)\end{array}$ \\
\hline $\begin{array}{l}\text { Factor Model } \\
p=4\end{array}$ & n.a. & n.a. & n.a. & $\begin{array}{l}2.8652 \\
(-413.58) \\
\end{array}$ \\
\hline
\end{tabular}




\begin{tabular}{|c|c|c|c|c|}
\hline \multicolumn{5}{|c|}{$\begin{array}{l}\text { Table 10: Rolling GDP Forecasting for } h=4 \\
\text { MSFEs as Proportion of Random walk MSFEs } \\
\text { Sums of log predictive likelihoods in parentheses }\end{array}$} \\
\hline & $n=3$ & $n=20$ & $n=40$ & $n=168$ \\
\hline $\begin{array}{l}\text { Minn. Prior } \\
\text { as in BGR }\end{array}$ & $\begin{array}{l}1.1324 \\
(-220.57)\end{array}$ & $\begin{array}{l}0.5852 \\
(-217.08)\end{array}$ & $\begin{array}{l}0.5284 \\
(-234.78)\end{array}$ & $\begin{array}{l}0.5297 \\
(-501.82)\end{array}$ \\
\hline $\begin{array}{l}\text { Minn. Prior } \\
\Sigma \text { diagonal }\end{array}$ & $\begin{array}{l}1.1324 \\
(-254.81)\end{array}$ & $\begin{array}{l}0.5869 \\
(-211.06)\end{array}$ & $\begin{array}{l}0.5404 \\
(-205.59)\end{array}$ & $\begin{array}{l}0.6019 \\
(-210.19)\end{array}$ \\
\hline $\begin{array}{l}\text { Minn. Prior } \\
\Sigma \text { not diagonal }\end{array}$ & $\begin{array}{l}1.1324 \\
(-261.78)\end{array}$ & $\begin{array}{l}0.5780 \\
(-210.55)\end{array}$ & $\begin{array}{l}0.5434 \\
(-206.41)\end{array}$ & $\begin{array}{l}0.5272 \\
(-202.72)\end{array}$ \\
\hline $\begin{array}{l}\text { SSVS Conjugate } \\
\text { semi-automatic }\end{array}$ & $\begin{array}{l}0.6254 \\
(-207.70)\end{array}$ & $\begin{array}{l}1.2338 \\
(-282.63)\end{array}$ & $\begin{array}{l}0.9471 \\
(-298.69)\end{array}$ & n.a. \\
\hline $\begin{array}{l}\text { SSVS Conjugate } \\
\text { plus Minn. Prior }\end{array}$ & $\begin{array}{l}1.3746 \\
(-260.57)\end{array}$ & $\begin{array}{l}0.6308 \\
(-230.23)\end{array}$ & $\begin{array}{l}0.5918 \\
(-246.17)\end{array}$ & n.a. \\
\hline $\begin{array}{l}\text { SSVS Non-conj. } \\
\text { semi-automatic }\end{array}$ & $\begin{array}{l}0.7815 \\
(-213.42)\end{array}$ & $\begin{array}{l}1.5985 \\
(-294.11)\end{array}$ & n.a. & n.a. \\
\hline $\begin{array}{l}\text { SSVS Non-conj. } \\
\text { plus Minn. Prior }\end{array}$ & $\begin{array}{l}1.3520 \\
(-250.28)\end{array}$ & $\begin{array}{l}0.63457 \\
(-209.89)\end{array}$ & n.a. & n.a. \\
\hline $\begin{array}{l}\text { Factor Model } \\
p=1\end{array}$ & n.a. & n.a. & n.a. & $\begin{array}{l}1.3232 \\
(-272.32)\end{array}$ \\
\hline $\begin{array}{l}\text { Factor Model } \\
p=4\end{array}$ & n.a. & n.a. & n.a. & $\begin{array}{l}7.0598 \\
(-576.28) \\
\end{array}$ \\
\hline \multicolumn{5}{|c|}{$\begin{array}{l}\text { Table 11: Rolling CPI Forecasting for } h=4 \\
\text { MSFEs as Proportion of Random walk MSFEs } \\
\text { Sums of log predictive likelihoods in parentheses }\end{array}$} \\
\hline & $n=3$ & $n=20$ & $n=40$ & $n=168$ \\
\hline $\begin{array}{l}\text { Minn. Prior } \\
\text { as in BGR }\end{array}$ & $\begin{array}{l}0.7059 \\
(-251.46)\end{array}$ & $\begin{array}{l}0.5484 \\
(-227.69)\end{array}$ & $\begin{array}{l}0.5596 \\
(-267.09)\end{array}$ & $\begin{array}{l}0.5144 \\
(-609.92)\end{array}$ \\
\hline $\begin{array}{l}\text { Minn. Prior } \\
\Sigma \text { diagonal }\end{array}$ & $\begin{array}{l}0.7059 \\
(-259.49)\end{array}$ & $\begin{array}{l}0.5499 \\
(-232.37)\end{array}$ & $\begin{array}{l}0.5641 \\
(-236.86)\end{array}$ & $\begin{array}{l}0.5552 \\
(-236.04)\end{array}$ \\
\hline $\begin{array}{l}\text { Minn. Prior } \\
\Sigma \text { not diagonal }\end{array}$ & $\begin{array}{l}0.7059 \\
(-243.84)\end{array}$ & $\begin{array}{l}0.5825 \\
(-222.21)\end{array}$ & $\begin{array}{l}0.5544 \\
(-227.63)\end{array}$ & $\begin{array}{l}0.5089 \\
(-219.32)\end{array}$ \\
\hline $\begin{array}{l}\text { SSVS Conjugate } \\
\text { semi-automatic }\end{array}$ & $\begin{array}{l}0.5190 \\
(-201.80)\end{array}$ & $\begin{array}{l}0.9892 \\
(-284.27)\end{array}$ & $\begin{array}{l}0.9127 \\
(-295.55)\end{array}$ & n.a. \\
\hline $\begin{array}{l}\text { SSVS Conjugate } \\
\text { plus Minn. Prior }\end{array}$ & $\begin{array}{l}0.6936 \\
(-226.87)\end{array}$ & $\begin{array}{l}0.5371 \\
(-221.23)\end{array}$ & $\begin{array}{l}0.5256 \\
(-244.04)\end{array}$ & n.a. \\
\hline $\begin{array}{l}\text { SSVS Non-conj. } \\
\text { semi-automatic }\end{array}$ & $\begin{array}{l}0.5740 \\
(-209.79)\end{array}$ & $\begin{array}{l}1.2194 \\
(-266.18)\end{array}$ & n.a. & n.a. \\
\hline $\begin{array}{l}\text { SSVS Non-conj. } \\
\text { plus Minn. Prior }\end{array}$ & $\begin{array}{l}0.6761 \\
(-214.78)\end{array}$ & $\begin{array}{l}0.5097 \\
(-201.30)\end{array}$ & n.a. & n.a. \\
\hline $\begin{array}{l}\text { Factor Model } \\
p=1\end{array}$ & n.a. & n.a. & n.a. & $\begin{array}{l}0.8195 \\
(-252.24)\end{array}$ \\
\hline $\begin{array}{l}\text { Factor Model } \\
p=4\end{array}$ & n.a. & n.a. & n.a. & $\begin{array}{l}2.1861 \\
(-436.09) \\
\end{array}$ \\
\hline
\end{tabular}




\begin{tabular}{|c|c|c|c|c|c|c|}
\hline \multicolumn{7}{|c|}{$\begin{array}{l}\text { Table 12: Rolling FFR Forecasting for } h=4 \\
\text { MSFEs as Proportion of Random walk MSFEs } \\
\text { Sums of log predictive likelihoods in parentheses }\end{array}$} \\
\hline & & $n=3$ & $n=20$ & \multicolumn{2}{|l|}{$n=40$} & $n=168$ \\
\hline \multicolumn{2}{|c|}{$\begin{array}{l}\text { Minn. Prior } \\
\text { as in BGR }\end{array}$} & $\begin{array}{l}0.9833 \\
(-255.70)\end{array}$ & $\begin{array}{l}0.5847 \\
(-213.38)\end{array}$ & \multicolumn{2}{|c|}{$\begin{array}{l}0.5621 \\
(-237.84)\end{array}$} & $\begin{array}{l}0.5770 \\
(-551.63)\end{array}$ \\
\hline \multicolumn{2}{|c|}{$\begin{array}{l}\text { Minn. Prior } \\
\Sigma \text { diagonal }\end{array}$} & $\begin{array}{l}0.9833 \\
(-324.87)\end{array}$ & $\begin{array}{l}0.5882 \\
(-246.61)\end{array}$ & \multicolumn{2}{|c|}{$\begin{array}{l}0.6049 \\
(-238.02)\end{array}$} & $\begin{array}{l}0.7154 \\
(-258.66)\end{array}$ \\
\hline \multicolumn{2}{|c|}{$\begin{array}{l}\text { Minn. Prior } \\
\Sigma \text { not diagonal }\end{array}$} & $\begin{array}{l}0.9833 \\
(-269.62)\end{array}$ & $\begin{array}{l}0.5825 \\
(-212.12)\end{array}$ & \multicolumn{2}{|c|}{$\begin{array}{l}0.6026 \\
(-206.50)\end{array}$} & $\begin{array}{l}0.5757 \\
(-213.01)\end{array}$ \\
\hline \multicolumn{2}{|c|}{$\begin{array}{l}\text { SSVS Conjugate } \\
\text { semi-automatic }\end{array}$} & $\begin{array}{l}0.5851 \\
(-207.19)\end{array}$ & $\begin{array}{l}1.3205 \\
(-273.83)\end{array}$ & \multicolumn{2}{|c|}{$\begin{array}{l}1.1668 \\
(-275.46)\end{array}$} & n.a. \\
\hline \multicolumn{2}{|c|}{$\begin{array}{l}\text { SSVS Conjugate } \\
\text { plus Minn. Prior }\end{array}$} & $\begin{array}{l}0.9152 \\
(-241.89)\end{array}$ & $\begin{array}{l}0.6059 \\
(-213.50)\end{array}$ & \multicolumn{2}{|c|}{$\begin{array}{l}0.5674 \\
(-228.79)\end{array}$} & n.a. \\
\hline \multicolumn{2}{|c|}{$\begin{array}{l}\text { SSVS Non-conj. } \\
\text { semi-automatic }\end{array}$} & $\begin{array}{l}0.5516 \\
(-197.78)\end{array}$ & $\begin{array}{l}1.6380 \\
(-268.75)\end{array}$ & \multicolumn{2}{|l|}{ n.a. } & n.a. \\
\hline \multicolumn{2}{|c|}{$\begin{array}{l}\text { SSVS Non-conj. } \\
\text { plus Minn. Prior }\end{array}$} & $\begin{array}{l}0.9083 \\
(-228.57)\end{array}$ & $\begin{array}{l}0.5830 \\
(-198.07)\end{array}$ & \multicolumn{2}{|l|}{ n.a. } & n.a. \\
\hline \multicolumn{2}{|c|}{$\begin{array}{l}\text { Factor Model } \\
p=1\end{array}$} & n.a. & n.a. & \multicolumn{2}{|l|}{ n.a. } & $\begin{array}{l}1.2547 \\
(-273.95)\end{array}$ \\
\hline \multicolumn{2}{|c|}{$\begin{array}{l}\text { Factor Model } \\
p=4\end{array}$} & n.a. & n.a. & \multicolumn{2}{|l|}{ n.a. } & $\begin{array}{l}3.7353 \\
(-514.91)\end{array}$ \\
\hline \multicolumn{7}{|c|}{ le 13: Summary of Best Forecasting Models } \\
\hline \multicolumn{7}{|c|}{ ng MSFE to Measure Forecast Performance } \\
\hline$=1$, rec. & \multicolumn{2}{|c|}{$\begin{array}{l}\text { Minn. Prior } \\
\text { as in BGR, } n=40\end{array}$} & \multicolumn{2}{|c|}{$\begin{array}{l}\text { Minn. Prior } \Sigma \text { not } \\
\text { diag., } n=20\end{array}$} & \multicolumn{2}{|c|}{$\begin{array}{l}\text { Minn. Prior as in } \\
\text { BGR, } n=40\end{array}$} \\
\hline$=4$, rec. & \multicolumn{2}{|c|}{$\begin{array}{l}\text { Minn. Prior } \\
\text { as in BGR, } n=168\end{array}$} & \multicolumn{2}{|c|}{$\begin{array}{l}\text { SSVS Non-conj plus } \\
\text { Minn. Prior, } n=3\end{array}$} & \multicolumn{2}{|c|}{$\begin{array}{l}\text { SSVS Non-conj. } \\
\text { semi-auto., } n=3\end{array}$} \\
\hline$=1$, roll. & \multicolumn{2}{|c|}{$\begin{array}{l}\text { SSVS Conj. plus } \\
\text { Minn. Prior, } n=40\end{array}$} & \multicolumn{2}{|l|}{ Minn. Prior } & & $\begin{array}{l}\text { S Conj. plus } \\
\text { n. Prior, } n=20\end{array}$ \\
\hline 4, roll. & $\begin{array}{l}\text { Minn. P } \\
\text { diagona }\end{array}$ & $\begin{array}{l}\text { ior, } \Sigma \text { not } \\
n=168\end{array}$ & $\begin{array}{l}\text { Minn. Prior } \\
\text { diagonal, } n=\end{array}$ & $\begin{array}{l}\sum \text { not } \\
=168\end{array}$ & & $\begin{array}{l}\text { S Non-conj. } \\
\text { i-auto., } n=3\end{array}$ \\
\hline Pred. & ikes. to & asure For & t Performanc & & & \\
\hline 1 , rec. & $\begin{array}{l}\text { Minn. P } \\
\text { BGR, } n\end{array}$ & $\begin{array}{l}\text { ior as in } \\
=40\end{array}$ & $\begin{array}{l}\text { Minn. Prior } \\
\Sigma \text { diag., } n=\end{array}$ & & & $\begin{array}{l}\text { S Conj. plus } \\
\text { n. Prior, } n=20\end{array}$ \\
\hline 4 , rec. & $\begin{array}{l}\text { SSVS N } \\
\text { semi-aut }\end{array}$ & $\begin{array}{l}\text { n-conj. } \\
\text {. } n=3\end{array}$ & $\begin{array}{l}\text { SSVS Non-ce } \\
\text { Minn. Prior, }\end{array}$ & $\begin{array}{l}\text { nj plus } \\
n=3\end{array}$ & & $\begin{array}{l}\text { S Non-conj plus } \\
\text { n. Prior, } n=3\end{array}$ \\
\hline 1, roll. & $\begin{array}{l}\text { Minn. } \mathrm{P} \\
\text { diagona }\end{array}$ & $\begin{array}{l}\text { ior } \sum \text { not } \\
n=168\end{array}$ & $\begin{array}{l}\text { SSVS Non-ce } \\
\text { semi-auto., } r\end{array}$ & & & $\begin{array}{l}\text { S Conjugate } \\
\text { i-auto., } n=20\end{array}$ \\
\hline roll. & $\begin{array}{l}\text { Minn. } \mathrm{P} \\
\text { diagona }\end{array}$ & $\begin{array}{l}\text { ior } \sum \text { not } \\
n=168\end{array}$ & $\begin{array}{l}\text { SSVS Conju } \\
\text { semi-auto., } r\end{array}$ & & & $\begin{array}{l}\text { S Non-conj. } \\
\text { i-auto., } n=3\end{array}$ \\
\hline
\end{tabular}




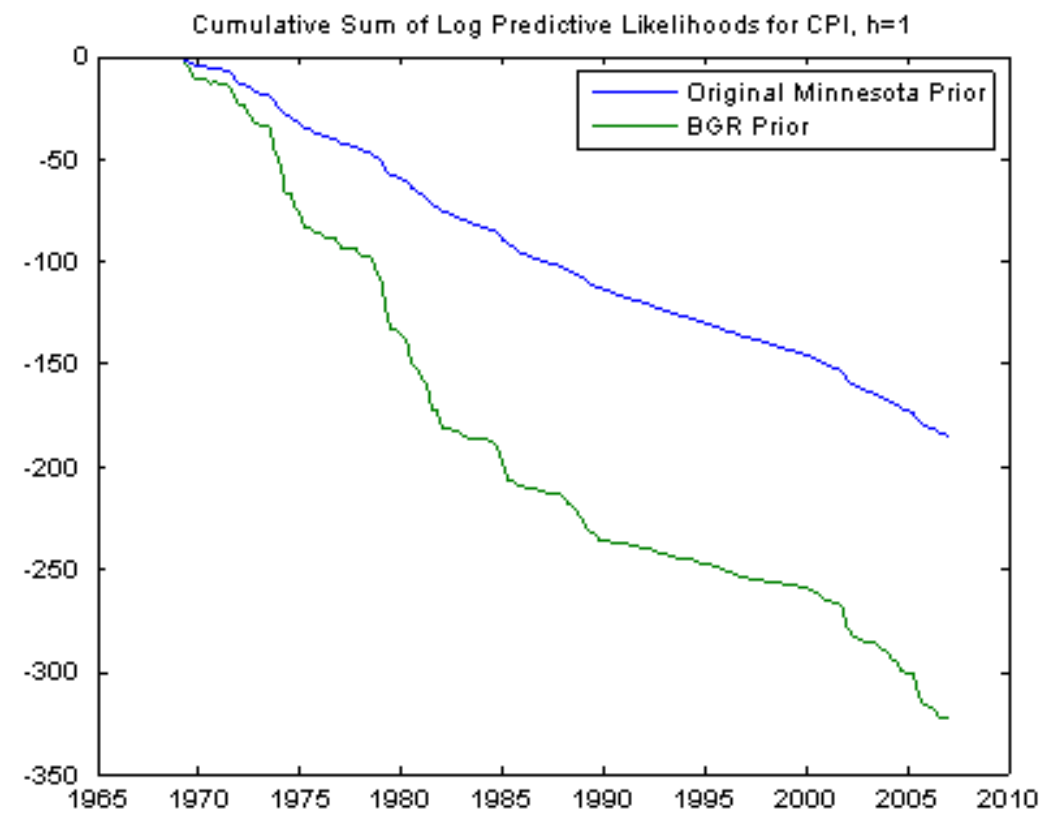

Figure 1

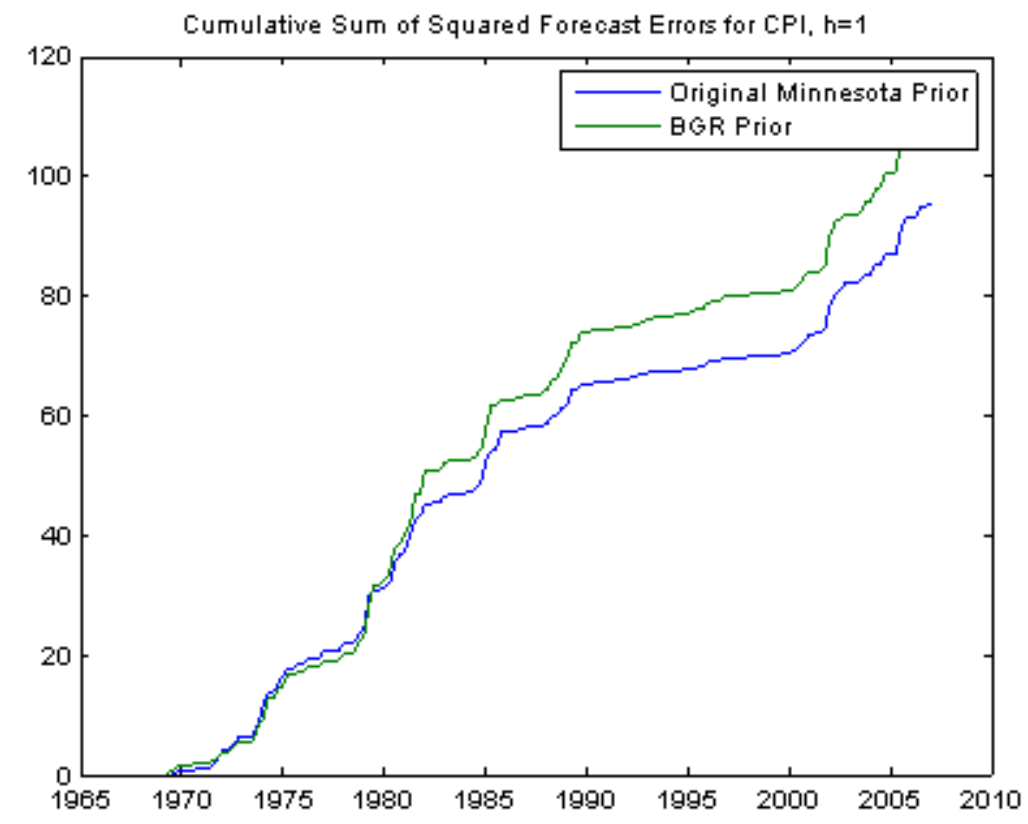

Figure 2

\section{Conclusions}

The literature contains a variety of priors which have been used with small VARs. In this paper, we have discussed the issues which arise when we attempt to use these priors with 
medium and large VARs. These issues are both computational and theoretical. The computational issues arise since priors which are not conjugate (or are only conditionally conjugate) typically require the use of posterior simulation methods. Non-conjugate priors typically have properties which are, in theory, more attractive. However, the researcher runs into computational problems which can be substantial (in the case of VARs with 20-40 dependent variables) or prohibitive (in the case of VARs with 50 or more dependent variables). The theoretical issues arise since the various priors shrink forecasts to different degrees and in different ways. A careful balancing of these computational and theoretical concerns is crucial to any sensible empirical analysis. This paper provides theoretical and empirical evidence relating to how this balancing might be done.

In particular, this paper presents several priors which have the potential for being useful for VAR forecasting. We focus on the classes of Minnesota and SSVS priors. The properties of these priors are discussed with emphasis on the issues which arise when moving from small to medium to large VARs. Our empirical exercise suggests that Bayesian VARs do tend to forecast better than factor methods. But there is no single prior which consistently leads to the best forecasting performance.

There is no theoretical reason for saying that one prior should be a better than another. Our different priors are similar in spirit, but do shrinkage in different ways. And it is risky to generalize based on the results from one empirical study (albeit one with an important and commonly-used data set). With these qualifications in mind, our empirical results do offer some useful insights on which priors might work well in certain cases (but not in others) and suggest that the use of a wide variety of priors is potentially desirable. In this paper, we have not done forecast averaging (e.g. using Bayesian model averaging where all models have the same likelihood function and differ only in their prior), but our results suggest that such an approach might be useful in dealing with the wide range of possible prior choices, the manner in which they do shrinkage and the uncertainty over which prior leads to the best forecast performance. 


\section{References}

Banbura, M., Giannone, D. and Reichlin, L. (2010). "Large Bayesian Vector Auto Regressions," Journal of Applied Econometrics, 25, 71-92.

Brown, P., Vannucci, M. and Fearn, T. (1998). "Multivariate Bayesian variable selection and prediction," Journal of the Royal Statistical Society B, 60, 627-641.

Christiano, L., Eichenbaum, M. and Evans C. (1999). "Monetary policy shocks: what have we learned and to what end?" Handbook of Macroeconomics, Vol. 1, ch. 2, p. 65-148, Taylor J., Woodford M. (eds). Elsevier: Amsterdam.

Doan, T., Litterman, R. and Sims, C. (1984). "Forecasting and conditional projection using realistic prior distributions," Econometric Reviews, 3, 1-144.

Forni, M., Hallin, M., Lippi, M. and Reichlin, L. (2003). "Do financial variables help forecasting inflation and real activity in the Euro Area?" Journal of Monetary Economics, 50, 1243-1255.

George, E., Sun, D. and Ni, S. (2008). "Bayesian stochastic search for VAR model restrictions," Journal of Econometrics, 142, 553-580.

Geweke, J. and Amisano, J. (2009). "Hierarchical Markov normal mixture models with applications to financial asset returns," Journal of Applied Econometrics, forthcoming.

Jochmann, M., Koop, G. and Strachan, R. (2009). "Bayesian forecasting using stochastic search variable selection in a VAR subject to breaks," International Journal of Forecasting, forthcoming.

Kadiyala, K. and Karlsson, S. (1997). "Numerical methods for estimation and inference in Bayesian VAR models," Journal of Applied Econometrics, 12, 99-132.

Koop, G. and Potter, S. (2004). "Forecasting in dynamic factor models using Bayesian model averaging," The Econometrics Journal, 7, 550-565.

Korobilis, D. (2009). "Forecasting in Vector Autoregressions with many predictors," Advances in Econometrics, vol. 23: Bayesian Macroeconometrics, forthcoming.

Litterman, R. (1986). "Forecasting with Bayesian vector autoregressions - Five years of experience," Journal of Business and Economic Statistics, 4, 25-38.

Marcellino, M., Stock, J. and Watson, M. (2006). "A comparison of direct and iterated multistep AR methods for forecasting macroeconomic time series," Journal of Econometrics, 135, 499-526.

Poirier, D. (1998). "Revising beliefs in non-identified models," Econometric Theory, 14, 483-509.

Stock, J. and Watson, M. (2002). "Macroeconomic forecasting using diffusion indexes," Journal of Business and Economic Statistics, 20, 147-162.

Stock, J. and Watson, M. (2006). "Forecasting using many predictors," pp. 515-554 in Handbook of Economic Forecasting, Volume 1, edited by G. Elliott, C. Granger and A. Timmerman, Amsterdam: North Holland.

Stock, J. and Watson, M. (2008). "Forecasting in dynamic factor models subject to structural instability," in The Methodology and Practice of Econometrics, A Festschrift in Honour of Professor David F. Hendry, edited by J. Castle and N. Shephard, Oxford: Oxford University Press. 


\section{Appendix A: Technical Details}

MCMC Algorithm for the VAR with Non-conjugate SSVS Prior

Posterior computation in the VAR with SSVS prior can be carried out using the MCMC algorithm described in George, Sun and Ni (2008). We use notation where $\theta$ denotes all the parameters in the VAR with non-conjugate SSVS prior and $\theta_{(-a)}$ denotes all the parameters except for $a$. For the notation used in this appendix, please refer to Section 2.2.

For the VAR coefficients we have

$$
\alpha \mid Y, \theta_{(-\alpha)} \sim N\left(\bar{\alpha}, \bar{V}_{\alpha}\right),
$$

where

$$
\begin{gathered}
\bar{V}_{\alpha}=\left[\Sigma^{-1} \otimes\left(X^{\prime} X\right)+D^{-1}\right]^{-1}, \\
\bar{\alpha}=\bar{V}_{\alpha}\left[D^{-1} \underline{\alpha}+\operatorname{vec}\left(X^{\prime} Y \Sigma^{-1}\right)\right] .
\end{gathered}
$$

The conditional posterior for $\gamma$ has $\gamma_{j}$ being independent (for all $j$ ) Bernoulli random variables:

$$
\begin{array}{r}
\operatorname{Pr}\left[\gamma_{j}=1 \mid Y, \theta_{\left(-\gamma_{j}\right)}\right]=\bar{q}_{j}, \\
\operatorname{Pr}\left[\gamma_{j}=0 \mid Y, \theta_{\left(-\gamma_{j}\right)}\right]=1-\bar{q}_{j},
\end{array}
$$

where

$$
\bar{q}_{j}=\frac{\frac{1}{\kappa_{1 j}} \exp \left(-\frac{\alpha_{j}^{2}}{2 \kappa_{1 j}^{2}}\right) \underline{q}_{j}}{\frac{1}{\kappa_{1 j}} \exp \left(-\frac{\alpha_{j}^{2}}{2 \kappa_{1 j}^{2}}\right) \underline{q}_{j}+\frac{1}{\kappa_{0 j}} \exp \left(-\frac{\alpha_{j}^{2}}{2 \kappa_{0 j}^{2}}\right)\left(1-\underline{q}_{j}\right)} .
$$

For the error covariance matrix, we begin with the following decomposition:

$$
\Sigma^{-1}=\Psi \Psi^{\prime},
$$

where $\Psi$ is upper-triangular. We use a Gamma prior for the square of each of the diagonal elements of $\Psi$ and the SSVS mixture of normals prior for each element above the diagonal. Note that this implies that the diagonal elements of $\Psi$ are always included in the model, ensuring a positive definite error covariance matrix.

Let the non-zero elements of $\Psi$ be labelled as $\psi_{i j}$ and define $\psi=\left(\psi_{11}, . ., \psi_{n n}\right)^{\prime}$, $\eta_{j}=\left(\psi_{1 j}, . ., \psi_{j-1, j}\right)^{\prime}$ for $j=2, . ., n$ and $\eta=\left(\eta_{2}^{\prime}, . ., \eta_{n}^{\prime}\right)^{\prime}$. For the diagonal elements of $\Psi$, we assume prior independence from each other and:

$$
\psi_{j j}^{2} \sim G\left(\underline{a}_{j}, \underline{b}_{j}\right),
$$

where $G\left(\underline{a}_{j}, \underline{b}_{j}\right)$ denotes the Gamma distribution with mean $\underline{a}_{j} / \underline{b}_{j}$ and variance $\underline{a}_{j} / \underline{b}_{j}^{2}$. Since all are variables have been normalized to have mean zero and standard deviation one, reasonable but relatively noninformative choices are $\underline{a}_{j}=1.0$ and $\underline{b}_{j}=1.0$. Our empirical results are robust to moderately large changes in these prior hyperparameters. 
The hierarchical prior for the off-diagonal elements of $\Psi$ takes the same mixture of normals form as $\alpha$. In particular, the SSVS prior has

$$
\eta_{j} \mid \omega_{j} \sim N\left(0, F_{j}\right)
$$

where $\omega_{j}=\left(\omega_{1 j}, . ., \omega_{j-1, j}\right)^{\prime}$ is a vector of unknown parameters with typical element $\omega_{i j} \in\{0,1\}$, and $F_{j}=\operatorname{diag}\left(f_{1 j}, . ., f_{j-1, j}\right)$ where

$$
f_{i j}=\left\{\begin{array}{c}
\kappa_{0 i j}^{2} \text { if } \omega_{i j}=0 \\
\kappa_{1 i j}^{2} \text { if } \omega_{i j}=1
\end{array},\right.
$$

for $j=2, . ., n$ and $i=1, . ., j-1$. Reasonable small and large prior hyperparameter values are $\kappa_{0 i j}=0.1$ and $\kappa_{1 i j}=1.0$.

For $\omega=\left(\omega_{2}^{\prime}, . ., \omega_{n}^{\prime}\right)^{\prime}$, the SSVS prior posits that each element has a Bernoulli form (independent of the other elements of $\omega$ ) and, hence, we have

$$
\begin{aligned}
& \operatorname{Pr}\left(\omega_{i j}=1\right)=\underline{q}_{i j}, \\
& \operatorname{Pr}\left(\omega_{i j}=0\right)=1-\underline{q}_{i j} .
\end{aligned}
$$

We make the default choice of $\underline{q}_{i j}=0.5$ for all $j$ and $i$ so that, a priori, each parameter is equally likely to be included or excluded.

The conditional posterior for $\psi$ can be obtained by noting that the conditional posterior for $\psi_{j j}^{2}$ (for $j=1, \ldots, n$ ) are independent of one another with

$$
\psi_{j j}^{2} \mid Y, \theta_{\left(-\psi_{j j}\right)} \sim G\left(a_{j}+\frac{T}{2}, \bar{b}_{j}\right)
$$

where

$$
\bar{b}_{j}=\left\{\begin{array}{l}
b_{1}+\frac{v_{11}}{2}, \text { if } j=1, \\
b_{1}+\frac{1}{2}\left\{v_{j j}-v_{j}^{\prime}\left[V_{j-1}+\left(F_{j}\right)^{-1}\right]^{-1} v_{j}\right\}, \text { if } j=2, \ldots, n .
\end{array}\right.
$$

The preceding equation uses notation where

$$
V=(Y-X A)^{\prime}(Y-X A)
$$

has elements $v_{i j}, v_{j}=\left(v_{1 j}, \ldots, v_{j-1, j}\right)^{\prime}$ and $V_{j}$ is the upper left $j \times j$ block of $V$.

The conditional posterior of $\eta$ can be written in terms of the conditional posteriors of $\eta_{j}$ (for $j=2, \ldots, n$ ) being independent of one another with:

$$
\eta_{j} \mid Y, \theta_{\left(-\eta_{j}\right)} \sim N\left(\bar{\eta}_{j}, \bar{V}_{j}\right)
$$

where

$$
\bar{V}_{j}=\left[V_{j-1}+F_{j}^{-1}\right]
$$

and

$$
\bar{\eta}_{j}=-\psi_{j j} \bar{V}_{j} v_{j}
$$

Finally, the conditional posterior for $\omega$ has $\omega_{i j}$ being independent (for all $i j$ ) Bernoulli random variables: 


$$
\begin{aligned}
& \operatorname{Pr}\left[\omega_{i j}=1 \mid Y, \theta_{\left(-\omega_{i j}\right)}\right]=\bar{q}_{i j}, \\
& \operatorname{Pr}\left[\omega_{i j}=0 \mid Y, \theta_{\left(-\omega_{i j}\right)}\right]=1-\bar{q}_{i j},
\end{aligned}
$$

where

$$
\bar{q}_{i j}=\frac{\frac{1}{\kappa_{1 i j}} \exp \left(-\frac{\psi_{i j}^{2}}{2 \kappa_{1 i j}^{2}}\right) \underline{q}_{i j}}{\frac{1}{\kappa_{1 i j}} \exp \left(-\frac{\psi_{i j}^{2}}{2 \kappa_{1 i j}^{2}}\right) \underline{q}_{i j}+\frac{1}{\kappa_{0 i j}} \exp \left(-\frac{\psi_{i j}^{2}}{2 \kappa_{0 i j}^{2}}\right)\left(1-\underline{q}_{i j}\right)} .
$$

In summary, an MCMC algorithm for the VAR with non-conjugate SSVS prior involves sequentially drawing from (16), (17), (23), (24) and (25).

Posterior Simulation Algorithm for the VAR with Conjugate SSVS Prior

The formula for posterior and predictive densities for the VAR with natural conjugate prior are given in Section 2.1 of the paper. For the VAR with conjugate SSVS prior, they can be interpreted as holding, conditional on $\widetilde{\gamma}$. Thus, all that is required is $p(\widetilde{\gamma} \mid Y)$. Using standard formula for the marginal likelihood for the multivariate Normal regression model and a noninformative prior for $\widetilde{\gamma}$ we obtain:

$$
p(\widetilde{\gamma} \mid Y) \propto\left(\left|D_{\gamma}\right|\left|\bar{V}^{-1}\right|\right)^{-\frac{n}{2}}|\bar{S}|^{-\frac{T+n+\underline{\nu}-1}{2}}
$$

We use the posterior simulation algorithm described on page 634 of Brown, Vannucci and Fearn (1998) to draw from $\widetilde{\gamma}$. 


\section{Appendix B: Data}

The data set used in this paper is an updated version of that used in Stock and Watson (2008) and the reader is referred to that paper for more details about the data. The raw data runs from 1959Q1 through 2008Q4. Variables which are originally at a monthly frequency are transformed to a quarterly by averaging over the three months in a quarter. Except for financial variables, variables are seasonally adjusted. All variables are transformed to stationarity as in Stock and Watson (2008). The following table provides a brief description of each variable along with a transformation code. This code is: $1=$ no transformation, $2=$ first difference, $3=$ second difference, $4=\log$, $5=$ first difference of logged variables, $6=$ second difference of logged variables.

\begin{tabular}{|l|l|l|l|l|}
\hline \multicolumn{5}{|l|}{ Table B1: Three Main Variables used in All VARs } \\
\hline Short Name & Mnemonic & Code & \multicolumn{1}{l|}{ Description } \\
\hline RGDP & GDP251 & 5 & \multicolumn{2}{l|}{ Real GDP, Quantity Index (2000=100) } \\
\hline CPI & CPIAUCSL & 6 & \multicolumn{2}{l|}{ CPI All Items } \\
\hline FFR & FYFF & 2 & \multicolumn{3}{|l|}{ Interest rate: Federal funds (effective) (\% per annum) } \\
\hline \hline Table B2: Remaining Variables used in VARs with 20 or more Variables \\
\hline Short Name & Mnemonic & Code & Description \\
\hline Com: spot price (real) & PSCCOMR & 5 & Real spot market price index: all commodities \\
\hline Reserves nonbor & FMRNBA & 3 & Depository inst reserves: nonborrowed (mil\$) \\
\hline Reserves tot & FMRRA & 6 & Depository inst reserves: total (mil\$) \\
\hline M2 & FM2 & 6 & Money stock: M2 (bil\$) \\
\hline Cons & GDP252 & 5 & Real Personal Cons. Exp., Quantity Index \\
\hline IP: total & IPS10 & 5 & Industrial production index: total \\
\hline Capacity Util & UTL11 & 1 & Capacity utilization: manufacturing (SIC) \\
\hline U: all & LHUR & 2 & Unemp. rate: All workers, 16 and over (\%) \\
\hline HStarts: Total & HSFR & 4 & Housing starts: Total (thousands) \\
\hline PPI: fin gds & PWFSA & 6 & Producer price index: finished goods \\
\hline PCED & GDP273 & 6 & Personal Consumption Exp.: price index \\
\hline Real AHE: goods & CES275R & 5 & Real avg hrly earnings, non-farm prod. workers \\
\hline M1 & FM1 & 6 & Money stock: M1 (bil\$) \\
\hline S\&P: indust & FSPIN & 5 & S\&P's common stock price index: industrials \\
\hline 10 yr T-bond & FYGT10 & 2 & Interest rate: US treasury const. mat., 10-yr \\
\hline Ex rate: avg & EXRUS & 5 & US effective exchange rate: index number \\
\hline Emp: total & CES002 & 5 & Employees, nonfarm: total private \\
\hline
\end{tabular}




\begin{tabular}{|l|l|l|l|}
\hline Table B3: Remaining Variables used in VARs with 40 or more Variables \\
\hline Short Name & Mnemonic & Code & Description \\
\hline SPREAD & SFYGT10 & 1 & Spread btwn 10 year and 3 month T-bill rates \\
\hline Consumer expect & HHSNT & 2 & Univ of Mich index of consumer expectations \\
\hline PMI & PMI & 1 & Purchasing managers' index \\
\hline NAPM vendor del & PMDEL & 1 & NAPM vendor deliveries index (\%) \\
\hline NAPM com price & PMCP & 1 & NAPM commodity price index (\%) \\
\hline GPDInv & GDP256 & 5 & Real gross private domestic investment \\
\hline Labor Prod & LBOUT & 5 & Output per hr: all persons, business sec \\
\hline NAPM Invent & PMNV & 1 & NAPM inventories index (\%) \\
\hline Exports & GDP263 & 5 & Real exports \\
\hline Imports & GDP264 & 5 & Real imports \\
\hline Gov & GDP265 & 5 & Real govt cons expenditures \& gross investment \\
\hline Emp. Hours & LBMNU & 5 & Hrs of all persons: nonfarm business sector \\
\hline NAPM new ordrs & PMNO & 1 & NAPM new orders index (\%) \\
\hline Cons credit & CCINRV & 6 & Consumer credit outstanding: nonrevolving \\
\hline BUSLOANS & BUSLOANS & 6 & Comm. and industrial loans at all comm. banks \\
\hline NAPM prodn & PMP & 1 & NAPM production index (\%) \\
\hline PCED-SERV-HOUS & GDP276_1 & 6 & Housing price index \\
\hline SalestoDomPurc & GDP270 & 5 & Real final sales to domestic purchasers \\
\hline Cons-Dur & GDP253 & 5 & Real personal cons expenditures: Durable goods \\
\hline Help wanted indx & LHEL & 2 & Index of help-wanted ads in newspapers \\
\hline
\end{tabular}




\begin{tabular}{|l|l|l|l|}
\hline \multicolumn{5}{|l|}{ Table B4: Remaining Variables used only in VARs with 168 Variables } \\
\hline Short Name & Mnemonic & Code & Description \\
\hline Cons-NonDur & GDP254 & 5 & Real personal consumption exp: nondur goods \\
\hline Cons-Serv & GDP255 & 5 & Real personal consumption exp: services \\
\hline FixedInv & GDP257 & 5 & Real gross priv domestic inv: fixed inv \\
\hline NonResInv & GDP258 & 5 & Real gross priv domestic inv: nonresidential \\
\hline NonResInv-Struct & GDP259 & 5 & Real gross priv domestic inv: nonres structures \\
\hline NonResInv-Bequip & GDP260 & 5 & Real gross priv domestic inv: nonres equip \\
\hline Res.Inv & GDP261 & 5 & Real gross priv domestic inv: residential \\
\hline Gov Fed & GDP266 & 5 & Real gov cons exp \& gross inv: federal \\
\hline Gov State/Loc & GDP267 & 5 & Real gov cons exp \& gross inv: state and local \\
\hline FinalSales & GDP268 & 5 & Real final sales of domestic product \\
\hline DomPurchases & GDP269 & 5 & Real gross domestic purchases \\
\hline RGNP & GDP271 & 5 & Real gross national product \\
\hline PGDP & GDP272 & 6 & Gross domestic product, price index \\
\hline PCED-Dur & GDP274 & 6 & Personal cons exp: durable goods, price index \\
\hline PCED-Ndur & GDP275 & 6 & Personal cons exp: nondur goods, price index \\
\hline PCED-Serv & GDP276 & 6 & Personal cons exp: services, price index \\
\hline PGPDI & GDP277 & 6 & Gross private domestic investment, price index \\
\hline PFixedInv & GDP278 & 6 & Gross priv dom inv: fixed inv, price index \\
\hline PNonResInv & GDP279 & 6 & Gross priv dom inv: nonresidential, price index \\
\hline PNonResStruc & GDP280 & 6 & Gross priv dom inv: nonres structures, price index \\
\hline PNonResEqu & GDP281 & 6 & Gross priv dom inv: nonres equipment, price index \\
\hline PResInv & GDP282 & 6 & Gross priv dom inv: residential, price index \\
\hline Pexp & GDP284 & 6 & Exports, price index \\
\hline Pimp & GDP288 & 6 & Imports, price index \\
\hline Pgov & 6 & Government cons exp \& gross inv, price index \\
\hline Pgov_Fed & 6 & Gov cons exp \& gross inv: federal, price index \\
\hline Pgov_stat/loc & GDP28 & 6 & Final sales of domestic product, price index \\
\hline P_FinSale & & \\
\hline
\end{tabular}




\begin{tabular}{|c|c|c|c|}
\hline Short Name & Mnemonic & Code & Description \\
\hline $\mathrm{P} \_$Purch & GDP290 & 6 & Gross domestic purchases, price index \\
\hline P_SalesPurc & GDP291 & 6 & Final sales to domestic purchasers, price index \\
\hline PGNP & GDP292 & 6 & Gross national product, price index \\
\hline Real Comp/Hour & LBPUR7 & 5 & Real comp per hour: employees, nonfarm business \\
\hline Unit Labor Cost & LBLCPU & 5 & Unit labor cost: nonfarm business sector \\
\hline PCED-DUR-MOTORVEH & GDP274_1 & 6 & Motor vehicles and parts, price index \\
\hline PCED-DUR-HHEQUIP & GDP274_2 & 6 & Furniture and household equipment, price index \\
\hline PCED-DUR-OTH & GDP274_3 & 6 & Other durables, price index \\
\hline PCED-NDUR-FOOD & GDP275_1 & 6 & Food, price index \\
\hline PCED-NDUR-CLTH & GDP275_2 & 6 & Clothing and shoes, price index \\
\hline PCED-NDUR-ENERGY & GDP275_3 & 6 & Gas, fuel oil, and other energy goods, price index \\
\hline PCED-NDUR-OTH & GDP275_4 & 6 & Other nondurables, price index \\
\hline PCED-SERV-HOUSOP & GDP276_2 & 6 & Household operation, price index \\
\hline PCED-SERV-H0-ELGAS & GDP276_3 & 6 & Electricity and gas, price index \\
\hline PCED-SERV-HO-OTH & GDP276_4 & 6 & Other household operation, price index \\
\hline PCED-SERV-TRAN & GDP276_5 & 6 & Transportation, price index \\
\hline PCED-SERV-MED & GDP276_6 & 6 & Medical care, price index \\
\hline PCED-SERV-REC & GDP276_7 & 6 & Recreation, price index \\
\hline PCED-SERV-OTH & GDP276_8 & 6 & Other services, price index \\
\hline PEXP-GOODS & GDP284_1 & 6 & Exports of goods, price index \\
\hline PEXP-SERV & GDP284_2 & 6 & Exports of services, price index \\
\hline PIMP-GOODS & GDP285_1 & 6 & Imports of goods, price index \\
\hline PIMP-SERV & GDP285_2 & 6 & Imports of services, price index \\
\hline IP: products & IPS11 & 5 & Industrial production index: products total \\
\hline IP: final prod & IPS299 & 5 & Industrial production index: final products \\
\hline IP: cons gds & IPS12 & 5 & Industrial production index: consumer goods \\
\hline IP: cons dble & IPS13 & 5 & Industrial production index: consumer durable \\
\hline IP:cons nondble & IPS18 & 5 & Industrial production index: consumer nondur \\
\hline
\end{tabular}




\begin{tabular}{|c|c|c|c|}
\hline Short Name & Mnemonic & Code & Description \\
\hline IP: bus eqpt & IPS25 & 5 & Industrial production index: business equipment \\
\hline IP: matls & IPS32 & 5 & Industrial production index: materials \\
\hline IP: dble mats & IPS34 & 5 & Industrial production index: dur goods materials \\
\hline IP:nondble mats & IPS38 & 5 & Industrial production index: nondur goods materials \\
\hline IP: $\mathrm{mfg}$ & IPS43 & 5 & Industrial production index: manufacturing \\
\hline IP: res util & IPS307 & 5 & Industrial production index: residential utilities \\
\hline IP: fuels & IPS306 & 5 & Industrial production index: fuels \\
\hline AHE: goods & CES275 & 6 & Avg hrly earnings, prod wrkrs, nonfarm-goods prod \\
\hline AHE: const & CES277 & 6 & Avg hrly earnings, prod wrkrs, nonfarm-construction \\
\hline AHE: $\mathrm{mfg}$ & CES278 & 6 & Avg hrly earnings, prod wrkrs, nonfarm-manufacturing \\
\hline Real AHE: const & CES277R & 5 & Real avg hrly earnings, prod wrkrs, nonfarm-const \\
\hline Real AHE: mfg & CES278R & 5 & Real avg hrly earnings, prod wrkrs, nonfarm-manuf \\
\hline Emp: gds prod & CES003 & 5 & Employees, nonfarm: goods-producing \\
\hline Emp: mining & CES006 & 5 & Employees, nonfarm: mining \\
\hline Emp: const & CES011 & 5 & Employees, nonfarm: construction \\
\hline Emp: $\mathrm{mfg}$ & CES015 & 5 & Employees, nonfarm: manufacturing \\
\hline Emp: dble gds & CES017 & 5 & Employees, nonfarm: durable goods \\
\hline Emp: nondbles & CES033 & 5 & Employees, nonfarm: nondurable goods \\
\hline Emp: services & CES046 & 5 & Employees, nonfarm: service providing \\
\hline Emp: TTU & CES048 & 5 & Employees, nonfarm: trade, transport and utilities \\
\hline Emp: wholesale & CES049 & 5 & Employees, nonfarm: wholesale trade \\
\hline Emp: retail & CES053 & 5 & Employees, nonfarm: retail trade \\
\hline Emp: FIRE & CES088 & 5 & Employees, nonfarm: financial activities \\
\hline Emp: Govt & CES140 & 5 & Employees, nonfarm: government \\
\hline Help wanted/emp & LHELX & 2 & Ratio: Help-wanted ads to number unemployed \\
\hline Emp CPS total & LHEM & 5 & Civilian labor force employed, total \\
\hline Emp CPS nonag & LHHAG & 5 & Civilian labor force employed, nonagric ind. \\
\hline U: mean duration & LHU680 & 2 & Average unemployment duration (weeks) \\
\hline
\end{tabular}




\begin{tabular}{|l|l|l|l|}
\hline Table B4 (continued): Remaining Variables used only in VARs with 168 Variables \\
\hline Short Name & Mnemonic & Code & Description \\
\hline U $<5$ wks & LHU5 & 5 & Unemp by duration, persons unemp less than 5 wks \\
\hline U 5-14 wks & LHU14 & 5 & Unemp by duration, persons unemp btwn 5 and 14 wks \\
\hline U 15+ wks & LHU15 & 5 & Unemp by duration, persons unemp 15 wks or more \\
\hline U 15-26 wks & LHU26 & 5 & Unemp by duration, persons unemp btwn 15 and 26 wks \\
\hline U 27+ wks & LHU27 & 5 & Unemp by duration, persons unemp 27 wks or more \\
\hline Avg hrs & CES151 & 1 & Avg wkly hours, prod wrks, nonfarm goods-producing \\
\hline Overtime: mfg & CES155 & 2 & Avg weekly overtime hrs, prod wrkrs, nonfarm, manuf \\
\hline HAuth & HSBR & 4 & Housing authorized: total new private housing units \\
\hline HStarts: NE & HSNE & 4 & Housing starts: Northeast \\
\hline HStarts: MW & HSMW & 4 & Housing starts: Midwest \\
\hline HStarts: South & HSSOU & 4 & Housing starts: South \\
\hline HStarts: West & HSWST & 4 & Housing starts: West \\
\hline 3 mo T-bill & FYGM3 & 2 & Interest rate: US T-bills, sec mkt, 3-month \\
\hline 6 mo T-bill & FYGM6 & 2 & Interest rate: US T-bills, sec mkt, 6-month \\
\hline 1 yr T-bond & FYGT1 & 2 & Interest rate: US T-bills const maturities 1-yr \\
\hline 5 yr T-bond & FYGT5 & 2 & Interest rate: US T-bills const maturities 5-yr \\
\hline 10 yr T-bond & FYGT10 & 2 & Interest rate: US T-bills const maturities 10-yr \\
\hline Aaabond & FYAAAC & 2 & Bond yield: Moody's AAA corporate \\
\hline Baabond & FYBAAC & 2 & Bond yield: Moody's BAA corporate \\
\hline Spread6m3m & SFYGM6 & 1 & Spread: 6 month minus 3 month T-bill \\
\hline Spread1y3m & SYGT1 & 1 & Spread: 1 year minus 3 month T-bill \\
\hline Spreadaaa10y & SFYAAAC & 1 & Spread: AAA corporate minus 10 yr T-bill \\
\hline Spreadbaa10y & SFYBAAC & 1 & Spread: BAA corporate minus 10 yr T-bill \\
\hline MZM & MZMSL & 6 & MZM FRB St. Louis \\
\hline MB & FMFBA & 6 & Monetary base, adj for res requirement changes \\
\hline CPI-Core & CPILFESL & 6 & CPI less food and energy \\
\hline PCE-Core & PCEPILFE & 6 & PCE price index less food and energy \\
\hline
\end{tabular}




\begin{tabular}{|l|l|l|l|}
\hline \multicolumn{4}{|l|}{ Table B4 (continued): Remaining Variables used only in VARs with 168 Variables } \\
\hline Short Name & Mnemonic & Code & Description \\
\hline PPI: cons gds & PWFCSA & 6 & Producer price index: finished consumer goods \\
\hline PPI: int mat'ls & PWIMSA & 6 & Producer price index: interm mat supplies \& compone \\
\hline PPI: crude & PWCMSA & 6 & Producer price index: crude materials \\
\hline Real PPI: crude mat'ls & PWCMSAR & 5 & Real prod price index: crude mat (PWSMSA/PCEPIL \\
\hline Commod: spot price & PSCCOM & 6 & Spot market price index: all commodities \\
\hline PPI CrudeOil & PW561 & 6 & Producer price index: crude petroleum \\
\hline OilPrice (Real) & PW561R & 5 & PPI crude (relative to core PCE) (PW561/PCEPILFE \\
\hline Ex rate: Switz & EXRSW & 5 & Swiss francs per US $\$$ \\
\hline Ex rate: Japan & EXRJAN & 5 & Japanese yen per US $\$$ \\
\hline Ex rate: UK & EXRUK & 5 & Cents per pound \\
\hline Ex rate: Can & EXRCAN & 5 & Canadian $\$$ per US $\$$ \\
\hline S\&P 500 & FSPCOM & 5 & S\&P's common stock price index: composite \\
\hline S\&P div yield & FSDXP & 2 & S\&P's composite common stock: dividend yield \\
\hline S\&P PE ratio & FSPXE & 2 & S\&P's composite common stock: price-earnings ratio \\
\hline DJIA & FSDJ & 5 & Dow Jones industrial average common stock price \\
\hline Orders (ConsGoods) & MOCMQ & 5 & New orders (net): consumer goods and materials \\
\hline Orders (NDCapGoods) & MSONDQ & 5 & New orders: nondefense capital goods \\
\hline
\end{tabular}

